\title{
Theropods, Mesoeucrocodiles and Pterosaurs Found from the Latest Maastrichtian Vitakri Formation of Balochistan, Pakistan; Description with Large Photographs and Comparison with Coeval Taxa from Indo-Pakistan Subcontinent
}

\author{
Muhammad Sadiq Malkani \\ Geological Survey of Pakistan, Muzaffarabad, Azad Kashmir, Pakistan \\ Email: malkanims@yahoo.com
}

How to cite this paper: Malkani, M.S. (2020) Theropods, Mesoeucrocodiles and Pterosaurs Found from the Latest Maastrichtian Vitakri Formation of Balochistan, Pakistan; Description with Large Photographs and Comparison with Coeval Taxa from Indo-Pakistan Subcontinent. Open Journal of Geology, 10, 510-551. https://doi.org/10.4236/ojg.2020.105023

Received: April 9, 2020

Accepted: May 9, 2020

Published: May 12, 2020

Copyright $\odot 2020$ by author(s) and Scientific Research Publishing Inc. This work is licensed under the Creative Commons Attribution International License (CC BY 4.0).

http://creativecommons.org/licenses/by/4.0/

\begin{abstract}
Theropods, mesoeucrocodiles and pterosaurs (along with titanosaurian sauropods) are found in two overbank flood deposited mottled muds/shale units (alternated by meandering river deposited sandstone unit) of the latest Maastrichtian (67 - $66 \mathrm{Ma}$ ) Vitakri Formation, Barkhan District, Balochistan, Pakistan. These vertebrates coexisted under the Cretaceous-Paleogene boundary line of control and became extinct as mass extinction. Previously these taxa lack the detail description but here theropods, mesoeucrocodiles and pterosaur from Pakistan are being described well with large photographs which provide better understanding of fauna from Pakistan and comparison with coeval taxa from Indo-Pakistan subcontinent. These fauna with associated cranial and postcranial skeletons are significant for Gondwanan paleobiogeography and phylogenetic studies.
\end{abstract}

\section{Keywords}

Theropods, Mesoeucrocodiles, Pterosaurs, Latest Maastrichtian, Pakistan

\section{Introduction}

From the first bone of dinosaur to about 3000 bones and or pieces of bones of archosaurs explored since 2000 from more than 25 localities [1] in the Latest Cretaceous (Latest Maastrichtian 67 - 66 Mya) Vitakri Formation [2] [3] [4] [5] of Barkhan District, Balochistan Province, Pakistan [6]-[18]. Most of these bones 
belong to titanosaurs [6]-[12], [15] [16] [17] [18], however its minor but significant part belong to theropods (Figures 1-6), mesoeucrocodiles (Figures 7-12), and pterosaur (Figure 13). The maps of 25 localities were presented by [1]. The stream sediments washing and screening methods may also help to find micro vertebrates, and also teeth and small cranial materials of large vertebrates in Vitakri and adjoining regions of Sulaiman (middle Indus) basin, and Khadro-Bara and adjoining exposures of latest Cretaceous Pab and Vitakri formations exposed in the core axis of Lakhi (Laki) thrusted anticline which are in waiting due to security problems. The previous reports on theropods, mesoeucrocodiles and pterosaurs from Pakistan lack detailed description and large photographs. So here these theropods, mesoeucrocodiles and pterosaur from Pakistan are being updated and described well with large photographs for better understanding of the fauna from Pakistan, their paleobiogeographic assessment, comparisons, evolutionary and phylogenetic studies.

\section{Latest, Last and Youngest Theropod Dinosaurs from Pakistan}

Out of 13 medium to large bodied theropods from India and Pakistan, only half of these are restricted to some common elements. The comparisons of Pakistani and Indian theropods based on overlapping teeth, vertebral and limb elements are carried here. Further the correlation of overlapping postcranial materials of two Pakistani theropods Vitakridrinda and Vitakrisaurus with four Indian theropods like Rajasaurus [19], Rahiolisaurus [20], Ornithomimoides and Dryptosauroides [21] are also carried.

\subsection{Vitakridrinda sulaimani Theropod Dinosaur from Pakistan}

The systematic paleontology of Vitakridrinda sulaimani is as follows.

Dinosauria [22];

Theropoda [23];

Ceratosauria [24];

Abelisauroidea [25];

Vitakrisauridae [26];

Vitakridrinda [18];

Vitakridrinda sulaimani [18];

(Figures 1-3).

Holotype specimens (Figure 1) from Alam locality 19c or 19, and referred specimens (Figure 2, Figure 3) from the South Kinwa 4, Mari Bohri 15, Topkinwa 16 and Sangiali 1 localities [27] were found in latest Maastrichtian (67 - 66 Million years ago/Ma) Vitakri Formation of Fort Munro Group, Barkhan district, Balochistan Province, Sulaiman or middle Indus basin, central Pakistan. Genus Vitakridrinda honoring the Vitakri village host site; drinda is Urdu and Saraiki language word meaning predator. The species name Vitakridrinda sulaimani honour the host Sulaiman Range. These fossils are hosted in the Quetta museum of Geological Survey of Pakistan (GSP is institution abbreviation). 


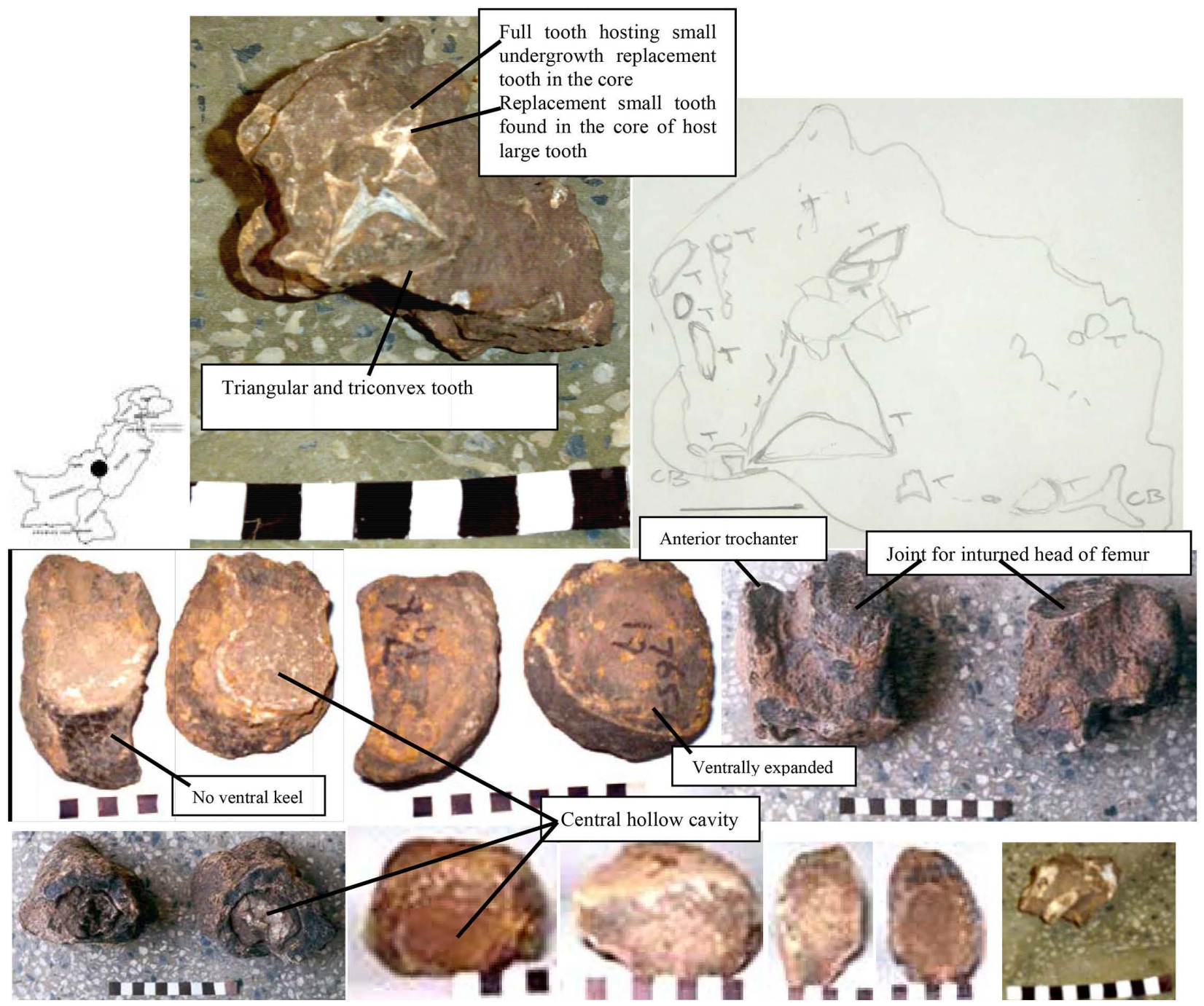

Figure 1. Vitakridrinda sulaimani holotypic fossils. Row 1, Map of Pakistan showing Vitakridrinda sulaimani holotypic Alam 19 or central Alam 19c type locality (black circle); Lumpy Specimen MSM-61-19 including holotypic more than 10 teeth and a few smaller cranial bones (photograph, centre; and line drawing, right). Row 2, holotypic tall dorsal centra MSM-706-19 and MSM-765-19 in 2 views and holotypic pair of left and right femora MSM-59-19 and MSM-60-19. Row 3, Cross sectional view of holotypic pair of left and right femora MSM-59-19 and MSM-60-19; distal femur cross section MSM-1039-19 in 4 views; teeth and cranial materials MSM-un-number-19. Scale, each/every black or white digit is 1 centimeter $(\mathrm{cm})$. Scale bar in line drawing is $2 \mathrm{~cm}$. Abbreviations; T, Tooth; CB, Cranial bone. The full specimen numbers are like GSP/MSM-59-19 to represent institution "Geological Survey of Pakistan" abbreviation (GSP) followed by collector M. Sadiq Malkani initials (MSM), central 59 is serial number and ending 19 is locality number of fossil. The specimen numbers are briefly represented like MSM-59-19. Further at places the fossil locality name followed by locality number is represented in work like Alam 19 or central Alam 19c locality, here Alam or central Alam is locality name and 19 or $19 \mathrm{c}$ is locality number (Pakistan dinosaur locality number). These localities with maps are presented by [1].

\subsubsection{Diagnosis of Vitakridrinda sulaimani Theropod}

Vitakridrinda sulaimani theropod overlapping features with most derived Abelisauroidea Ceratosauria are as broad, small and low crown teeth, large hollow cavity in the centre enveloped by thick peripheral limb bones and medium to large sized amphicoelous vertebrae. Because in Indo-Pakistan, the poripuchian (all caudals are procoelous except first biconvex in a few taxa [6] [7] [8]) the most derived or most advanced titanosaurs coexisted during latest Cretaceous which 
lack amphicoelous caudal vertebrae. Further Induszalim mesoeucrocodile have relatively very small vertebrae than Vitakridrinda and Vitakrisaurus theropods. Vitakridrinda sulaimani shares with Vitakrisauridae as dorsal centrum with parapophysis on the upper part of anterior caudal centra and forwardly inserted anteriorly neural arch on the dorsal aspect of centra.

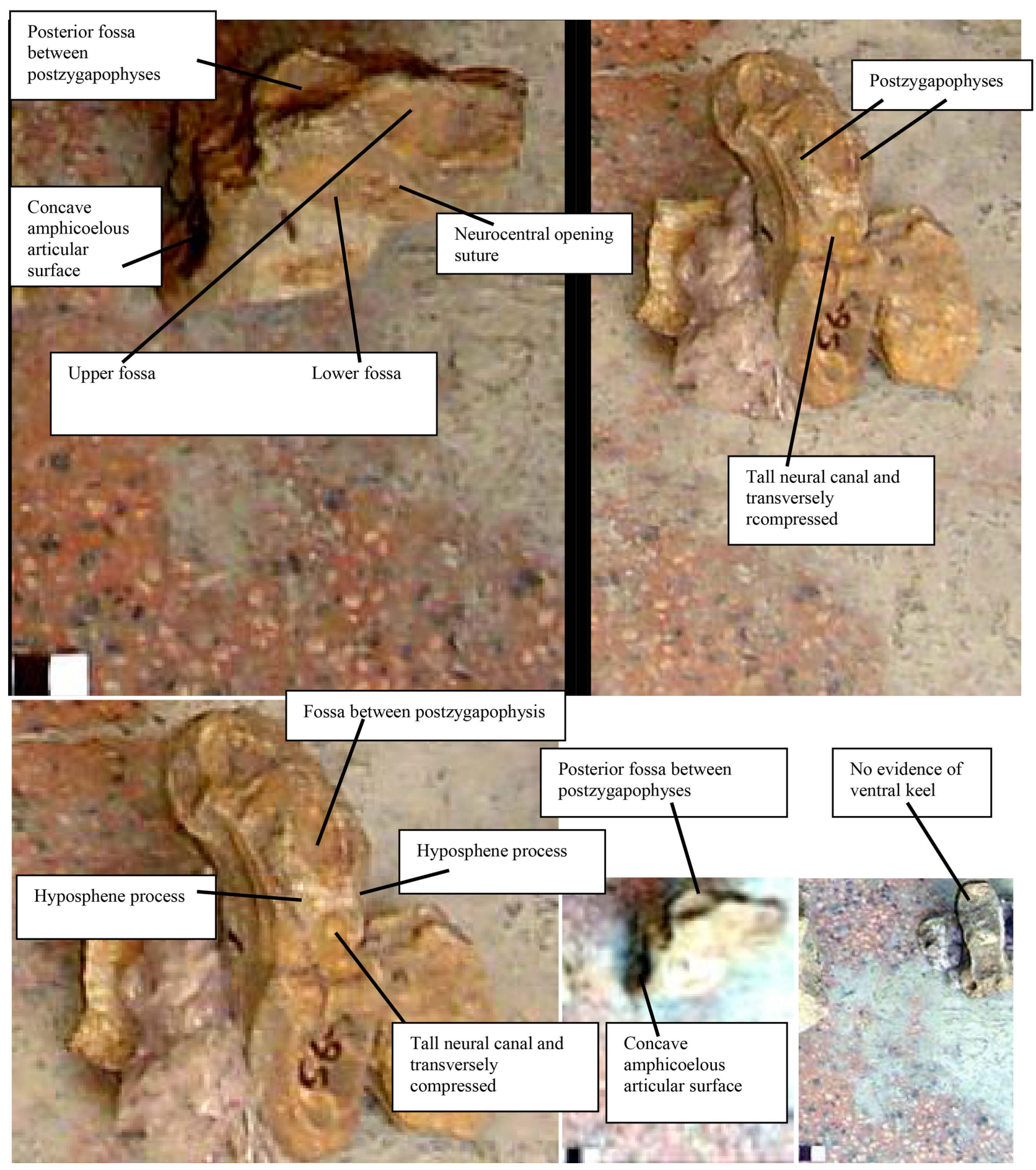

Figure 2. Vitakridrinda sulaimani referred fossil. Referred tall anterior dorsal vertebra MSM-56-1 in different views from Sangiali locality, Barkhan district, Balochistan, central Pakistan. Every black or white digit is $1 \mathrm{~cm}$. 


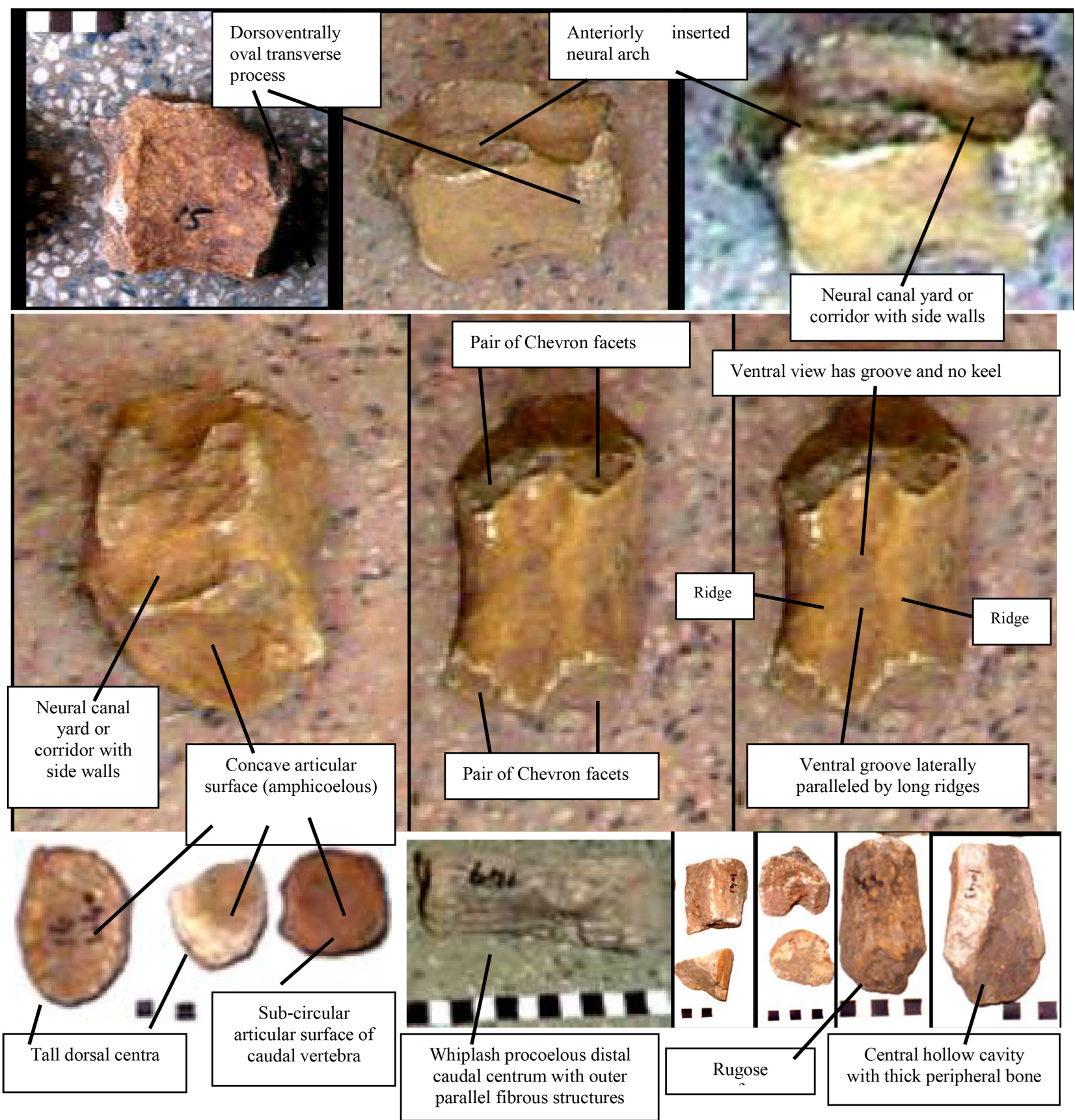

Figure 3. Vitakridrinda sulaimani referred fossils. Row 1, anterior caudal vertebra MSM-58-15 in lateral views. Row 2, anterior caudal vertebra MSM-58-15 in dorsal view (photo 1/p1) and ventral views (p2 and 3). Row 3, p1, tall dorsal vertebrae MSM-1040-16 and MSM-1048-16, sub-circular caudal centrum MSM-282-15; p2, distal caudal vertebra MSM-149-16 of whiplash tail; p3, p4, metatarsal II (MSM-41-16, upper; MSM-42-16, lower) in 2 views; p5, p6, metatarsal III (MSM-43-4) in 2 views. Scale, every black or white digit is $1 \mathrm{~cm}$.

Vitakridrinda sulaimani is characterised by the following autapomorphies. Vitakridrinda teeth are anteroposteriorly broad with low crown and have triangular shape with triconvex cross section. Asymmetric convexity (one limb shorter than other limb showing one limb shorter than other limb with different angles) found on one side, and plain surface is found on other side. Vitakridrinda teeth 
cavity is enveloped by two layer enamel; the blue enamel layer and then outer white enamel layer, while in mesoeucrocodiles from Pakistan only one layer enamel is observed. The blue enamel layer is sandwiched between the teeth cavity and outer white enamel layer. The central cavity of teeth of Vitakridrinda is relatively large (Figure 1) than teeth cavity of mesoeucrocodile Induszalim bala (Figure 11). The theropod teeth are compared with mesoeucrocodiles because the Vitakridrinda theropod and Induszalim mesoeucrocodile are found in one and same locality and same horizon. Outer cover and envelope on central hollow cavity of teeth of Vitakridrinda is relatively very thin (Figure 1), than the teeth of mesoeucrocodile Induszalim bala (Figure 11) which have very thick bone enamel envelope or cover. Vitakridrinda have low crown, oval to D-shaped and typically triangular to triconvex teeth. Vitakridrinda have elongated, tall and ventrally expanded dorsal vertebrae while Vitakrisaurus have elongated cylindrical dorsal vertebrae and Rajasaurus [19] have short and tall dorsal vertebrae. Vitakridrinda have elongated and square shaped to cylindrical caudal vertebrae while Vitakrisaurus have elongated and tall caudal vertebrae. Anteroposteriorly elongated fossa on upper part of lateral side of dorsal centrum and extended into neural arch. This fossa also has neurocentral opening and suture. Further another upper fossa is present on the adjoining anterodorsal side which is again anteroposteriorly elongated while in Rajasaurus [19] both fossa are anteroposteriorly compressed and dorsoventrally tall. Vitakridrinda hyposphene articulation found as extended laminae on dorsal vertebra. The postzygapophyses are vertical (not horizontal) and anteroposteriorly oriented (Figure 2) while in Rajasaurus postzygapophyses are horizontal and laterally oriented. Vitakridrinda have groove bounded by lateral ridge in ventral view of dorsal (Figure 2) and also anterior caudal vertebra (Figure 3), while Vitakrisaurus have groove bounded by lateral ridge in ventral view of caudal centra (Figure 5), Rajasaurus [19] and Rahiolisaurus [20] have no groove and no lateral bonded ridges in ventral views of dorsal and caudal vertebrae. Vitakridrinda did not have ventral keel in dorsal (Figure 1) (Figure 2) and also caudal centra (Figure 3), while Rajasaurus [19] and Rahiolisaurus [20] have ventral keel on dorsal and caudal centra. Anterior caudal have ventrodorsally oval shaped transverse process situated on the posterior articular ring. This oval transverse process is relatively thin in the ventral and thick in the mid and dorsal parts. Further this transverse process is not contacted with neural arch while in Vitakrisaurus and also in Rajasaurus [19] the transverse process is extended from centrum to the neural arch. Vitakridrinda has asymmetric oval shaped transverse processes (Figure 3), while Vitakrisaurus has subcircular transverse process and Rahiolisaurus have triangular (cross-section) transverse process. Neural arch on anterior caudal is forwardly inserted while some posterior part is not covered (Figure 3). Vitakridrinda neural canal is dorsoventrally tall suboval shaped in anterior caudal vertebrae while Vitakrisaurus neural canal is dorsoventrally compressed, transversely oval shaped in anterior caudal and also in middle caudal vertebrae. Vitakridrinda have amphicoelous biconcave caudal vertebrae (Figures 1-3), while Rajasaurus 
[19] and Rahiolisaurus [20] have amphiplatyan or flat articular surfaces or feeble amphicoely. Distal caudal is anteroposteriorly elongated subcylinder type with long parallel ridges alternated by long grooves on all sides (Figure 3), except the anterior and posterior concave articular surfaces. This distal centrum has no apparent neural arch connection. Femur shaft is transversely broad (Figure 1) with thick peripheral bone enveloped on the central hollow cavity (Figure 1). Femoral anterior trochanter is vertically oriented but blunted at tip (Figure 1).

\subsubsection{Description of Fossils of Vitakridrinda sulaimani Theropod}

Associated Teeth: Holotypic 10 teeth are exposed in irregular shaped lump holotypic specimen MSM-61-19 (Figure 1) which is about $8 \mathrm{~cm}$ long and $8 \mathrm{~cm}$ wide, found with bones of Vitakridrinda theropod, Induszalim mesoeucrocodile and Gspsaurus titanosaurs from central Alam type locality. The teeth in lump cannot be assigned to Gspsaurus titanosaur because the teeth in the Gspsaurus skull [7] are circular and totally different than lump teeth. The teeth of Induszalim are circular and arced asymmetric D-shaped laterally slightly concave and medially convex but not triconvex. Further Induszalim have teeth with one enamel layer while the teeth in lump have two enamel; the blue and outer white enamel layer. So the third fauna found is the Vitakridrinda theropod. So these lumpy teeth were assigned to Vitakridrinda theropod. Further these teeth are broad with low crown, which is the typical feature of abelisaurian theropods. These teeth are diagnostic and assigned with holotypic postcranial materials of Vitakridrinda which is again diagnostic. One labial convexity show both limb at about $90^{\circ}$ and other anterior and posterior convexities show limbs angle about $45^{\circ}$. Holotypic specimen MSM-61-19 includes one large tooth mostly exposed while many others are exposed as cross section. The large tooth is reduced transversely. Tooth crown is extremely low (significant character) and the ratio of the crown height to rostro-caudal width is about $1-1.5$. Tooth anteroposterior breadth is $2.2 \mathrm{~cm}$, labial to lingual depth is about $1.3 \mathrm{~cm}$. Teeth are found embedded in matrix so possible length seems to be low like $2.2 \mathrm{~cm}$ or slightly more as broad, this is interpreted due to seeing the decreasing tooth anteroposterior breadth. Teeth are heterodont and conical. About 5 teeth are short, asymmetrical triangular and triconvex, while others are oval and D-shaped teeth. $\mathrm{D}$-shaped teeth have one side flat and other side convex. The large hollow of teeth covered by a thin blue enamel layer and finally outer thin white enamel layer cover (significant character), while the mesoeucrocodile Induszalim bala which show relatively thin hollow with thick enamel white cover. Further one tooth has another replacement tooth inside showing replacement of teeth phenomena (Figure 1). A few cranial bones like eye peripheral bone/lacrimal and other trirays star like bones are also found in association with teeth in lumpy specimen (Figure 1).

Teeth are slightly recurved and taper gradually. The ratio of the crown height to antero-posterior width of the tooth base in fully erupted teeth is 1 to 1.5 (like Indosuchus), where as the other carnosaurs this ratio is 3 to 4 [28]. Morphology 
of the tooth may vary with position. In Majungasaurus [29], the premaxillary teeth are more compressed labiolingually with stronger development of both the mesial and distal keels coarse serrations. However, these distal serrations are absent in the preserved teeth of Rahiolisaurus [20]. Theropod teeth are some of the most diagnostic fossils from dinosaur assemblages with taxonomic utility to the genus or even species level [30]. Theropod teeth are common because theropod have more than 50 teeth and majority of these lacks root and represent shed teeth upon replacements [31]. Theropod teeth are abundant in the fossil record and broadly used at distinct levels of taxonomic classification [31] [32] [33].

The teeth of Vitakridrinda are triconvex and triangular and slight to strongly compressed sidewise to oval, while Indosuchus teeth are subequal antero-posterior and transverse diameter and highly compressed sidewise and noasaurid theropod teeth from Brazil which are elliptical [34]. Vitakridrinda teeth are triconvex with core large core cavity enveloped by blue enamel and then outer white enamel layer make differentiation from Indosuchus teeth and theropod teeth from India. Further replacement of teeth is also found in one tooth having developed another small tooth in the core of large tooth (Figure 1). Some slender teeth may belong to last maxillary teeth because [28] mentioned that the last four maxillary teeth are more slender. The reference [35] reported six distinct teeth of theropod which may belong to one taxon [19]. The teeth of Vitakridrinda are broad and less crown than Arcovenator escotae [36] from France who has teeth high $(3-5.5 \mathrm{~cm})$. Further Vitakridrinda has forwardly inserted neural arch on caudal centra while the Arcovenator escotae [36] has neural arch contact with caudal centra on most of the dorsal aspect of centra. The reference [36] mentioned that the paleobiogeographic closer affinity with Indo-Pakistan and Madagascar than South America. They further reported Arcovenator escotae more closely related to taxa from India and Madagascar than to South American forms.

Dorsal Vertebrae: Two holotypic partial dorsal centra MSM-706-19, MSM765-19 (Figure 1) from Alam, one referred dorsal vertebra MSM-56-1 (Figure 2) from Sangiali, and dorsal centra MSM-1040-16 and MSM-1048-16 (Figure 3) from Top Kinwa were found. The dorsal vertebra MSM-56-1 is $3.5 \mathrm{~cm}$ wide and $5.7 \mathrm{~cm}$ high while length is incomplete but seems to be elongate. The holotypic partial dorsal centra are tall (Figure 2) and their morphology provides clues to assign dorsal vertebrae (Figure 3) from Topkinwa and Sangiali localities. One vertebra MSM-56-1) from Sangiali include partial centrum and articulated neural arch (Figure 2) provide best information especially differentiation from Rajasaurus. The other centra only provide limited features especially of centrum. The dorsal centra are tall, amphicoelous, waisted and ventrally expanded and dorsally reduced. The dorsal view of posterior part of dorsal centrum is not covered by neural arch (Figure 2), it means the neural arch is inserted forwardly anteriorly. Vitakridrinda and Vitakrisaurus have elongated dorsal vertebrae (Figure 2) 
while Rajasaurus have short and tall dorsal vertebrae. Vitakridrinda centrum is devoid of double pleurocoels (Figure 2) unlike other abelisauroids (e.g. Carnotaurus, Majungasaurus, Laevisuchus) in which double pleurocoels are present. Vitakridrinda (and also Vitakrisaurus) did not have ventral keel (Figure 2) (Figure 3) on centra and in this regards differ from Rajasaurus, Rahiolisaurus and Nhandumirim which have longitudinal ventral keel on centra. Vitakridrinda have groove bounded by lateral ridge in ventral view of dorsal (Figure 2), while Vitakrisaurus has very feeble impression of groove and bounded lateral ridge (Figure 6), Rajasaurus [19] and Rahiolisaurus [20] have no groove and no lateral bonded ridges in ventral views of dorsal vertebrae. The anterior and posterior articular surfaces of the centrum of Vitakridrinda are subcircular and formed well developed amphicoelous concavity (Figure 2) (Figure 3) while the Rajasaurus and Rahiolisaurus have only slight concavity or mostly flat or feeble or gentle amphicoelous natures. Central core of centrum have sub circular hollow and peripheral thick bone known from the cross sectional view (Figure 1). The Vitakridrinda neural canal is vertically elongated suboval and transversely compressed (Figure 2) like Rajasaurus, and unlike Vitakrisaurus saraiki which has transversely elongated and dorsoventrally compressed neural canal (Figure 5).

Two large and lense shaped fossa like lower and upper fossa (Figure 2) are observed on the lateral side of dorsal vertebra. The lower fossa extended from dorsal margin of the centrum to the neural arch (Figure 2). The neurocentral opening suture is found close to the dorsal margin of fossa (Figure 2). Vitakridrinda has anteroposteriorly elongate lense shaped lower fossa (Figure 2) like Carnotaurus [37], and unlike Rajasaurus which has subtriangular shaped fossa [19]. The upper fossa is found just above lower fossa on lateral view (Figure 2) and bounded by dorsal and ventral laminae which trends anteroposteriorly. The upper fossa started just anterior of postzygapophysis. There are a number of small pneumatic diverticulae and several laminae that separate larger pneumatic fossae. On lateral view two postzygapophyseal laminae (postzygodiapophyseal lamina) started from postzygapophysis toward anteriorly and their divergence forms the dorsal fossa (Figure 2). In posterior view, paired laminae (spinoprezygapophyseal, spinopostzygapophyseal) enclose a narrow median fossa as they extend dorsally from the postzygapophyses to the neural spine (Figure 2). The postzygapophyses are longer anteroposteriorly than broad transversely and have an inclined orientation in Vitakridrinda while this orientation is horizontal in Rajasaurus. Short and vertical intrapostzygapophyseal laminae join each postzygapophysis to the hyposphene (Figure 2). The neural arch is highly pneumatic.

Anterior Caudal Vertebrae: Two anterior caudals MSM-58-15 and MSM-28215 found from Mari Bohri. The anterior caudal centrum MSM-58-15 (Figure 3) is $7.9 \mathrm{~cm}$ long, $5.6 \mathrm{~cm}$ wide and $6.2 \mathrm{~cm}$ high. The anterior caudal vertebrae are relatively short, slightly tall with subcircular articular rings, amphicoelous, slightly waisted and lack pleurocoel (Figure 3). In Vitakridrinda the neural 
arches are inserted anteriorly on dorsal surface of anterior caudal centra (Figure 3) while in Rajasaurus [19] the neural arch covers the most of dorsal surface of centrum. Vitakridrinda and Vitakrisaurus did not have ventral keel on the centra and in this regards differ from Rajasaurus, Rahiolisaurus and Nhandumirim which have longitudinal keel present on ventral surface of centrum. Vitakridrinda (and also Vitakrisaurus) have groove bounded by lateral ridge in ventral view of anterior caudal vertebra (Figure 3) (Figure 5), while Rajasaurus [19] and Rahiolisaurus [20] have no groove and no lateral bonded ridges in ventral views of caudal vertebrae. The cranial rim of the centrum is slightly more than the caudal articular surface. The centrum is in the shape of a subrectangular (Figure 3) and not show parallelogram in side view, however the anterior articular ring on the dorsal part is forwardly extended or offset. The transverse process is dorsoventrally oval shaped oriented on upper half of articular rim (Figure 3). The transverse process is found only on centrum and not connected with neural arch (Figure 3) in Vitakridrinda, while the transverse process is located laterally at base of neural arch and not located on centrum in Vitakrisaurus, it is partly on centrum and partly on neural arch in Rajasaurus. Vitakridrinda has asymmetric oval shaped transverse processes (Figure 3), while Vitakrisaurus has subcircular transverse process and Rahiolisaurus have triangular (cross-section) transverse process. Vitakridrinda have transverse process with dorsoventrally oval shaped while the thickness is increasing in the mid and dorsal portions (Figure 3). Because their distal ends are broken, it is not possible to infer if they were fan-shaped, a feature that occurs in most (e.g. Carnotaurus, Ilokelesia, Ekrixinatosaurus) but not all (e.g. Majungasaurus) abelisauroids. In Vitakridrinda the transverse process is separated from neural arch (Figure 3) while in Rajasaurus it is attached to neural arch. Well developed chevron facets (Figure 3) are observed in anterior and middle caudal centrum of Vitakridrinda, while Rajasaurus have no obvious chevron facets, although the ventral margins of the centrum are weathered [19]. Vitakridrinda have deeply concave amphicoelous caudal vertebrae (Figure 3), while Rajasaurus and Rahiolisaurus have almost flat or amphiplatyan or gently or feebly developed amphicoelous surfaces.

Distal Caudal Vertebra Showing Distal Whiplash Tail Nature: One distal caudal centrum MSM-149-16 (Figure 3) found from Topkinwa. This vertebra is $11 \mathrm{~cm}$ long and $3-4 \mathrm{~cm}$ wide. This vertebra is amphicoelous (biconcave, having concave both ends), sub cylindrical long, slender and lack pleurocoel (Figure 3) and also lack articular surface for neural arch (Figure 3) revealing position in distal tail. There are no any neural arches or chevron facets. It is simple whip lash type distal caudal vertebra. It has parallel longitudinal ridges/fibrous/laminar structures alternated by long grooves trending anteroposteriorly located on all sides except the anterior and posterior concave articular surfaces (Figure 3).

Femur: Holotypic proximal left and right femora MSM-59-19 and MSM-6019 and a distal femur shaft MSM-1039-19 (Figure 1) from Alam were collected. 
The preserved portions are the proximal shaft, anterior trochanter and subcircular head joint with shaft while interned head is broken. A pair of proximal femora shows hollow in the core and thick walled bone on the periphery. It shows evidence of inturned head with a distinct neck. Anterior trochanter is well developed and slightly blunted (Figure 1). Anteroposterior and transverse diameter of the central hollow cavity is about 5 and $5.5 \mathrm{~cm}$. Thickness of peripheral bone is $1 \mathrm{~cm}$ on the ventral side and $2.5 \mathrm{~cm}$ just below the inturned head (Figure 1). The femoral cross section just below the inturned head is slightly oval (Figure 3) having the anteroposterior and transverse maximum width as 7.5 and $9.5 \mathrm{~cm}$ respectively. Distal femur MSM-1039-19 (Figure 3) is transversely longer than anteroposteriorly like proximal femur. The transversely longer hollow and shaft and thick peripheral bone of distal femur matches with proximal femur show the same with originally one femur parts. The distal femur has core hollow cavity same as proximal part. This core cavity is enveloped by thick peripheral bone dorsal side but on ventral side fibrous bone network replaced the hollow, revealing close approach to fibular and tibial condyles. The femur shaft is compressed anteroposteriorly and longer transversely than anteroposteriorly (Figure 1). This animal may be $7-10 \mathrm{~m}$ long and weighed $5-10$ tons. Huene distinguished two types of femur and tibia like stouter to Indosaurus and slender to Indosuchus. This division is also found in Pakistan like Vitakridrinda has stouter limb bones with thick bone envelope on hollow cavity (Figure 1) and Vitakrisaurus has slender limb bones with thin bone envelope on hollow cavity (Figure 6). A low but slightly blunted anterior trochanter on femora (Figure 1) share with the femora of Carnotaurus, Ekrixinatosaurus, and Xenotarsosaurus.

Metatarsals: Referred partial metatarsal II (MSM-41-16 and MSM-42-16) and metatarsal III (MSM-1043-4) from Top Kinwa (Figure 3) were collected with the distal whiplash caudal vertebra MSM-149-16. Metatarsal II (MSM-41-16 and MSM-42-16) is relatively thicker than metatarsal III (Figure 3). These have central hollow cavity which is surrounded by thick peripheral bones (Figure 3). Its end is slightly inflated or expanded. Metatarsal II is a robust metapodial similar to that in Ceratosaurus [38] and basal tetanurans such as Allosaurus [39] and Sinraptor [40]. The proximal shaft is broader as in noasaurids [41]. The lateral view of proximal metatarsal II is convex and medial side is concave (Figure 3 ). Metatarsal III (MSM-1043-4) is relatively less thick than metatarsal II. This has central hollow cavity which is surrounded by thick peripheral bones (Figure 3 ). This is the reason for referring to Vitakridrinda because Vitakridrinda have thick peripheral bone and Vitakrisaurus have relatively thin peripheral bones. Its end is slightly inflated or expanded. This end has also some rugosity. Metatarsal III is a relatively slender metapodial. The end of metatarsal III is convex, asymmetric and rugose.

\subsection{Vitakrisaurus saraiki Theropod Dinosaur from Pakistan}

Systematic paleontology of Vitakrisaurus saraiki is as follows. 
Dinosauria [22];

Theropoda [23];

Ceratosauria [24];

Abelisauroidea [25];

Vitakrisauridae [26];

Vitakrisaurus [26];

Vitakrisaurus saraiki [26];

(Figures 4-6).
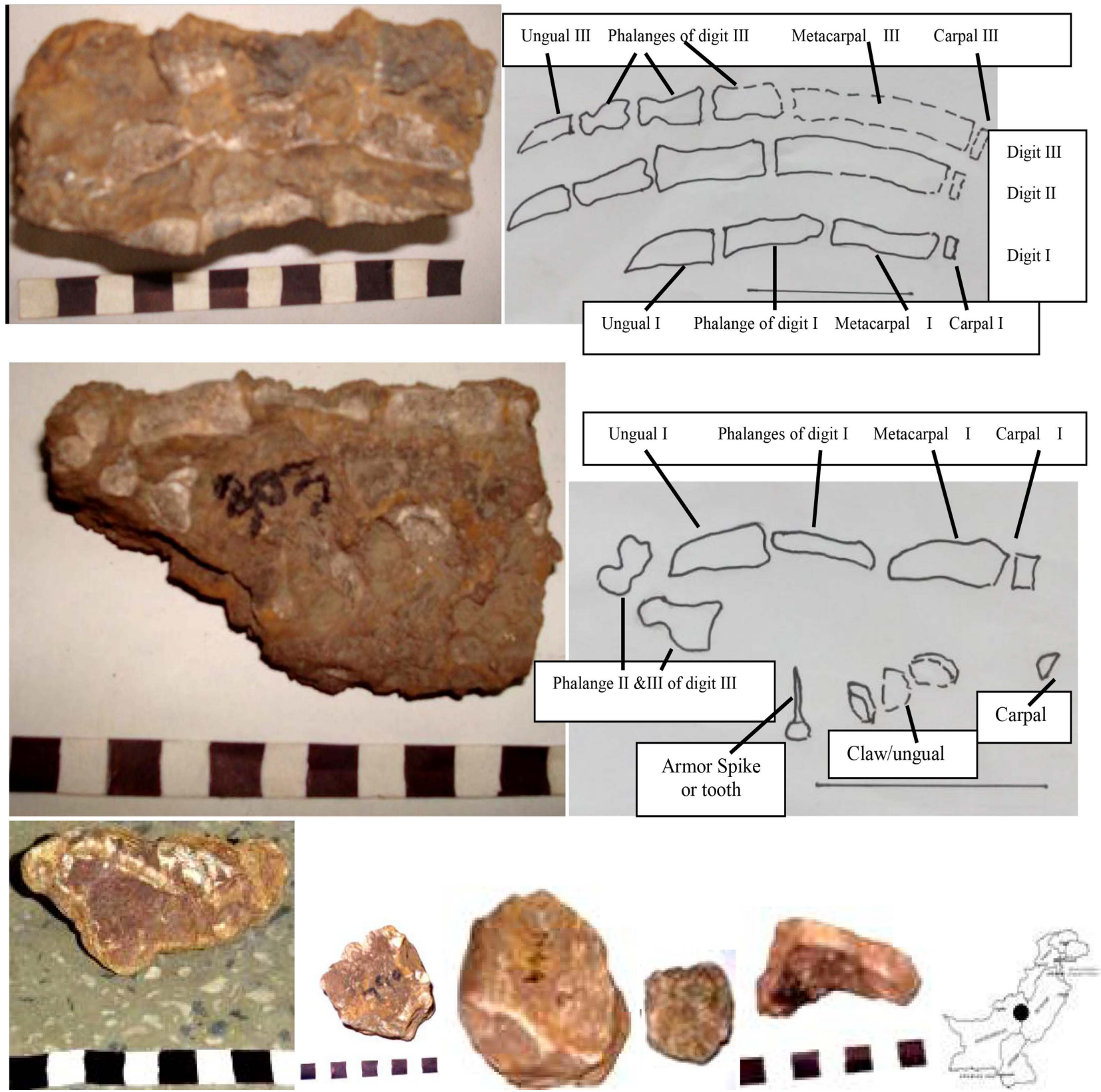

Figure 4. Vitakrisaurus saraiki holotypic fossils (in Figure 4 and Figure 5). Rows 1 and 2, right hand/manus MSM-303-2 in dorsal and medial views (left, image; right, line drawings). Row 3, proximal ulna MSM-1076-2 cross sectional view; partial vertebra MSM-780-2; humerus cross sectional bones MSM-1044-2, MSM-984-2 and MSM-1027-2; and map of Pakistan showing holotypic mid Bor type locality. Scale, every black or white digit is $1 \mathrm{~cm}$. Scale bar in line drawing is $5 \mathrm{~cm}$. 

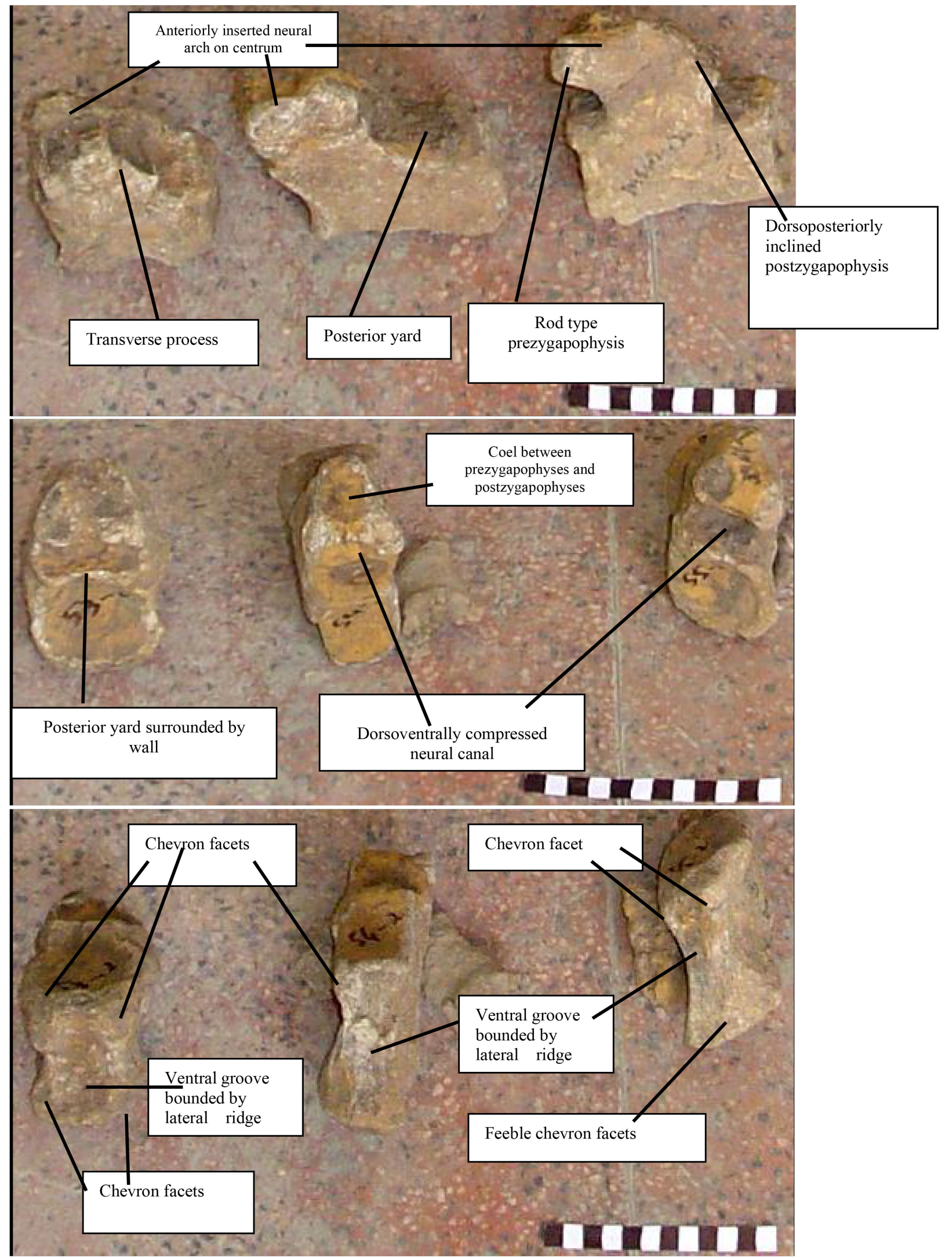

Figure 5. Vitakrisaurus saraiki holotypic fossils (in Figure 4 and Figure 5). Rows 1, 2 and 3, one anterior caudal MSM-53-2 and two mid-caudal vertebrae MSM-54-2 and MSM-55-2 in lateral, anterior and ventral views. Scale, every black or white digit is $1 \mathrm{~cm}$. 


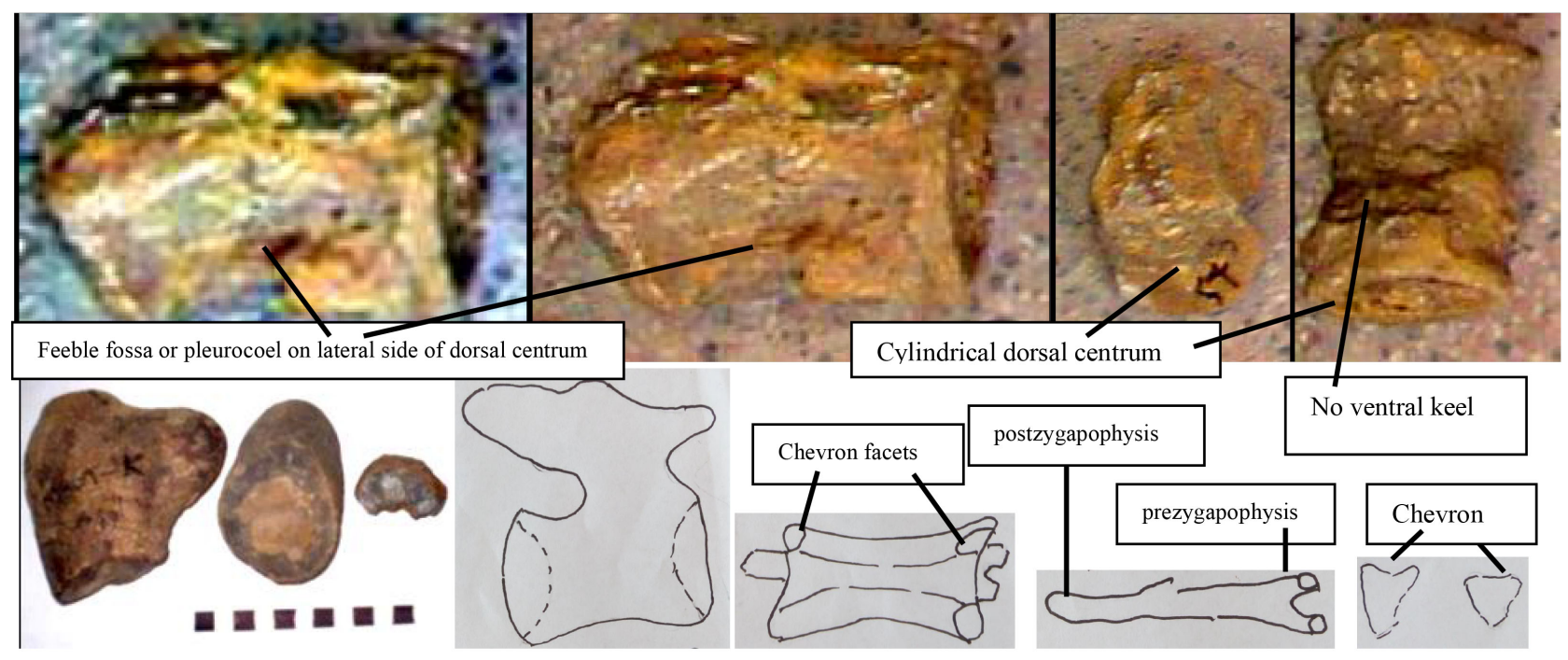

Figure 6. Vitakrisaurus saraiki referred fossils. Row 1, dorsal vertebra MSM-57-3 in lateral (2 photos), anterior and posteroventral views found from Shalghara 3 locality of Vitakri Dome area, Pakistan. Row 2, p1, proximal femur MSM-1049-K, mid cross section of femur MSM-1057-K and part of peripheral bone of leg section MSM-1059-K from Karkh locality, Khuzdar, Balochistan (Kirthar/lower Indus basin). P2-5, line drawings of tall amphicoelous caudal vertebra K 20/316 in right lateral and ventral views, its neural arch including prezygapophysis and postzygapophysis processes in dorsal view, and two small chevrons K 20/318 [21] from Bara Simla hill, Jubbulpore, India, here being referred to Vitakrisaurus saraiki large theropod. Scale; every black or white digit is 1 $\mathrm{cm}$.

Holotype specimens (Figure 4) (Figure 5) were collected from the mid Bor 2 locality and referred specimens (Figure 6) were collected from the Shalghara 3 locality in latest Maastrichtian (67 - 66 Million years ago) Vitakri Formation of Fort Munro Group, Barkhan district, Balochistan, Sulaiman or middle Indus basin, central Pakistan. An amphicoelous mid caudal vertebra (K20/316) and two chevrons (K20/318) (Figure 6) from Bara Simla hill, Jubbulpore, India [21] are being referred to Vitakrisaurus saraiki. The reason of referring is mentioned in description. Genus Vitakrisaurus honoring the village Vitakri; saurus means lizard. The species Vitakrisaurus saraiki name honour the Saraiki language of host Sulaiman Range and Daman areas. These holotypic and referred fossils from Pakistan are hosted in the Quetta museum of Geological Survey of Pakistan.

\subsubsection{Diagnosis of Vitakrisaurus saraiki Theropod}

The Vitakrisaurus saraiki [26] is a medium sized theropod dinosaurs sharing with the most derived Abelisauroidea, Ceratosauria as moderate to large limb bones with relatively large hollow cavity in the centre enveloped by relatively thin peripheral bones, amphicoelous nature of vertebrae and slightly recurved claw/ungual of hand. Further the amphicoelous vertebrae are medium sized, highly larger than mesoeucrocodiles, and slightly smaller than titanosaurian. In Indo-Pakistan the titanosaurs found so far are poripuchian in which anterior, mid and distal caudal vertebrae are procoelous (while in lithostrotian the anterior and mid caudals are procoelous) the most derived titanosaurs which have no amphicoelous vertebrae. So these amphicoelous vertebrae belong to abeli- 
sauroid ceratosaurian theropods. Vitakrisauridae (definition) is the clade containing Vitakrisaurus saraiki and Vitakridrinda sulaimani. Vitakrisauridae have the same characters as Vitakrisaurus saraiki.

Vitakrisaurus saraiki [26] has the following autapomorphic characters. Vitakrisaurus saraiki has cylindrical elongated dorsal centrum (Figure 6) jointed with neural arch on all dorsal view anteroposterior length, while Vitakridrinda has tall and anteroposteriorly elongated dorsal centra (Figure 1) (Figure 2) and Rajasaurus has tall and short dorsal centrum. Vitakrisaurus has circular or subcircular transverse process on lateral basal neural arch of anterior caudals, while Rajasaurus has transverse process which extended into neural arch, Vitakridrinda has oval shaped transverse process did not contacted with neural arch and located on upper part of posterior articular ring on anterior caudal centrum, and Rahiolisaurus has triangular transverse process. Vitakrisaurus has circular transverse process on base of neural arch (not found on centrum) of anterior caudals, while Rajasaurus have dorsoventrally elongated transverse process on centrum and also contacted with neural arch. Neural arch on anterior caudal is forwardly inserted (Figure 5) while in Rajasaurus the neural arch cover all along the dorsal surface of caudal centrum. Vitakrisaurus did not have ventral keel in dorsal centra (Figure 6) and also caudal (Figure 5) centra, while Rajasaurus and Rahiolisaurus have ventral keel on dorsal and caudal centra. Vitakrisaurus neural canal is dorsoventrally compressed, transversely oval shaped in anterior caudal and also in middle caudal vertebrae (Figure 5), while Rajasaurus neural canal is circular shaped in anterior caudal vertebrae. Vitakrisaurus anterior and midcaudal vertebrae have posterior yard (Figure 5) on the posterior vacant/uncover part of dorsal aspect of centrum. This yard is surrounded by laterally and posteriorly by thin boundary wall. Vitakrisaurus saraiki mid caudal centra did not have a longitudinal ridge on its lateral surface, and also did not have ventral keel in mid caudal centra (Figure 5) while Rajasaurus centrum bears a reduced longitudinal ridge on its lateral surface, and its ventral surface is keeled. Vitakrisaurus have leg bones like femur with thin peripheral bone on the central hollow cavity in cross section while Vitakridrinda have relatively thick peripheral bones on central hollow cavity of leg bones. Articulated and associated elements of manus/hand (Figure 4) (Figure 6) have thick bones. Metacarpal I is short and relatively narrow, metacarpal II is thickest and longest, and metacarpal III are thick and long but slightly less than metacarpal II. Manual phalange I of digit I is longest, phalange II-I and phalange II-II are thick and long, phalange III-I, phalange III-II and phalange III-III are short and expanded on proximal and distal ends. Manual ungual or claw I is thick, robust and slightly recurved downward (Figure 4).

\subsubsection{Description of Fossils of Vitakrisaurus saraiki Theropod}

Dorsal Vertebra: One referred dorsal vertebra MSM-57-3 (Figure 10) from Shalghara 3 is being referred to Vitakrisaurus. This circular dorsal centrum being different than Vitakridrinda, Rajasaurus and Rahiolisaurus dorsal centra, 
and its location Shalghara 3 is close to holotypic locality of Vitakrisaurus, so it is being assigned to Vitakrisaurus. This vertebra MSM-57-3 include complete centrum (Figure 6) and provide information especially differentiation from Vitakridrinda, Rajasaurus and Rahiolisaurus. This dorsal centrum is amphicoelous, slightly waisted and has lateral feeble fossa or pleurocoel (Figure 6). The centrum length is $6.6 \mathrm{~cm}$, width $6.6 \mathrm{~cm}$ and length $8.3 \mathrm{~cm}$ (Figure 6). This dorsal centrum is elongated cylindrical with circular shaped articular surfaces (Figure 6), while dorsal centra of Vitakridrinda is tall and elongated (Figure 6), and the dorsal centrum of Rajasaurus is tall and short. Vitakridrinda and Vitakrisaurus did not have ventral keel (Figure 2) (Figure 6) and in this regards differ from Rajasaurus, Rahiolisaurus and Nhandumirim which have longitudinal keel on ventral surface of centrum. The proximal and posterior articular surfaces of the centrum are circular and concave (Figure 6). They have slightly constriction and slight concave profiles of the ventral margin of centra in side view (Figure 6). The dorsal centrum is not spool-shaped, with its articular faces not deeper than broad while Rajasaurus dorsal centrum is spool-shaped, with its articular faces deeper than broad [19]. Vitakrisaurus have well developed amphicoelous concave articular surfaces (Figure 11) while the Rahiolisaurus [20] and Rajasaurus [19] have flat or gentle or faint amphicoelous nature. Vitakrisaurus has elongated dorsal centrum (Figure 6) jointed on all dorsal view anteroposterior length with neural arch.

Anterior Caudal Vertebra: A holotypic anterior caudal centrum MSM-53-2 (Figure 6) found from mid Bor locality. This centrum is $6.4 \mathrm{~cm}$ wide and $7.5 \mathrm{~cm}$ high. The anterior caudal vertebrae are relatively short, slightly tall to squarish, amphicoelous, slightly waisted and lack pleurocoel and ventral keel (Figure 6). The neural arches are inserted forward toward the anterior side on the dorsal aspect of anterior caudal centra (Figure 6). Vitakridrinda and Vitakrisaurus did not have ventral keel (Figure 2) (Figure 6) on ventral surface of centrum, and in this regards differ from Rajasaurus, Rahiolisaurus and Nhandumirim which have longitudinal ventral keel. The cranial and proximal surfaces of the centrum are slightly tall. The transverse process is located above the centrum and at the base of neural arch of Vitakrisaurus (Figure 5), while in Vitakridrinda it is found close to posterior rim of centrum and not extended into neural arch (Figure 3). The centrum has waisted concave profiles of the ventral margin in side view (Figure 5). The neural canal is transversely wide and dorsoventrally compressed in Vitakrisaurus (Figure 5), while in Vitakridrinda the neural canal is tall and transversely compressed (Figure 2). Chevron facets are well developed in anterior and also posterior end of centrum (Figure 6) of Vitakrisaurus saraiki, while Rajasaurus have no obvious chevron facets, although the ventral margins of the centrum are weathered [19].

Mid-Caudal Vertebrae: Two holotypic mid-caudals MSM-54-2 and MSM-55-2 (Figure 5) found from mid Bor locality. Further one mid-caudal vertebra K20/316 and two chevrons (K20/318) (Figure 6) from Bara Simla hill, Jubbulpore, India [21] are being referred to Vitakrisaurus saraiki due to its similarity 
with holotypic caudal vertebrae shape and characters from Pakistan and considering India and Pakistan as one land during latest Cretaceous. The reference [21] assigned this amphicoelous (biconcave) caudal vertebra K20/316 of [42] and two chevrons K20/318 to Titanosaurus indicus [43] titanosaur. It is necessary to mention that Titanosaurus indicus [43] can not be used synonym because of dual affinity, one vertebra to Titanosaurs due to procoelous nature and another vertebra to theropods due to amphicoelous biconcave nature. But now we know that the titanosaurs from the latest Cretaceous of Pakistan are Poripuchian in which all tail vertebrae are procoelous (except first biconvex first caudal in a few taxa), while not lithostrotian in which anterior and mid caudals are procoelous. Poripuchians are most derived titanosaurs having full caudal row as procoelous (except first biconvex caudal of a few taxa) while the said vertebra K20/316 (Figure 6) is amphicoelous biconcave. Its characters like tallness, strong amphicoely, occurrence of well developed chevron facets, ventral groove (without sagital keel) and size matches with Vitakrisaurus saraiki midcaudal vertebrae (Figure 5). Further chevrons are different than titanosaurs and their size is small, so this vertebra and small sized chevrons are being referred to Theropod Vitakrisaurus saraiki. Further this amphicoelous vertebrae with well developed biconcave nature) and its forwarded inserted neural arch on centrum (Figure 6) similar to midcaudal of Vitakrisaurus saraiki (Figure 5). The caudal centrum MSM-54-2 is $8.2 \mathrm{~cm}$ high. The caudal centrum MSM-55-2 is $8.7 \mathrm{~cm}$ long, $5.5 \mathrm{~cm}$ wide and $7.0 \mathrm{~cm}$ high. The mid caudal vertebrae are amphicoelous, slightly waisted and lack pleurocoel and lack ventral keel (Figure 5). The caudal centra are long and tall (Figure 5). On dorsal centra the neural arches cover the most of the whole length (Figure 6) while in caudal centra the neural arch is anteriorly forwardly inserted (Figure 5). Vitakridrinda and Vitakrisaurus did not have ventral keel (Figure 3) (Figure 5) on ventral surface of centrum, and in this regards differ from Rajasaurus, Rahiolisaurus and Nhandumirim which have longitudinal keel. The mid caudals have waisted or concave profiles of the ventral margin of centra in side view (Figure 5). The lateral surfaces are flat (Figure 5). The Vitakrisaurus saraiki mid caudal centra did not have a reduced longitudinal ridge on its lateral surface (Figure 5) and also did not have ventral keel in mid caudal centra (Figure 5), while Rajasaurus centrum bears a reduced longitudinal ridge on its lateral surface, and its ventral surface is keeled. Both cranial and caudal articular surfaces of the centrum are concave (Figure 5), while Rajasaurus have amphiplatyan or gentle or feeble amphicoelous concavity. The mid caudals have feeble chevron facets as compared to anterior caudals which have well developed chevron pair of facets located on anterior and posterior articular rings ventral view (Figure 5). The proximal chevron of mid caudal vertebra shows very shallow haemal canal forming broad gentle limb of haemal arch (Figure 6). The proximal chevron is anteroposteriorly compressed (Figure 6. However the mid chevron is becoming single subcircular (Figure 5) and distal parts was broken. Neural arch on anterior caudal is forwardly inserted (Figure 5) while in Rajasaurus the neural arch cover all along the dorsal surface of cen- 
trum. Vitakrisaurus neural canal is dorsoventrally compressed, transversely oval shaped in anterior caudal and also in middle caudal vertebrae (Figure 5), while Vitakridrinda have tall and transversely compressed neural canal (Figure 3) and Rajasaurus neural canal is circular shaped in anterior caudal vertebrae. Vitakrisaurus anterior and midcaudal vertebrae have posterior yard (Figure 5) on the posterior vacant/uncover part of dorsal aspect of centrum. This yard is surrounded by laterally and posteriorly by thin boundary wall (Figure 5) and it is not found in caudal vertebra of Rajasaurus.

Limb Bones: Vitakrisaurus have leg bones with relatively thin peripheral bone on the central hollow cavity in cross section (Figure 4, Figure 6) while Vitakridrinda have thick peripheral bones on hollow cavity of leg bones (Figure 1).

Humerus: Holotypic humerus cross sections MSM-1044 -2, MSM-984-2 and MSM-1027-2 (Figure 4) found from mid Bor. The distal humerus cross section show transversely broad humerus and anterior part section shows posterior convexity. Central hollow cavity enveloped by relatively thin bone (Figure 4), while Vitakridrinda have thick peripheral bone in limb elements (Figure 1).

Ulna: A proximal right ulna just adjoining/below the proximal end MSM1076-2 (Figure 4) is collected mid Bor locality. It has central cavity which is subparallel to the outer morphology (Figure 4). The central cavity is trirays (Figure 4) and also shows diverticulums. The outer morphology represents trirays structures. Its medial portion is relatively flat while the lateral portion has one ray extended lateroanteriorly for the attachment of radius. Its shaft is transversely broad and flattened medially (Figure 4). This element has no parallel in Rajasaurus [19].

Hand/Manus: Holotypic right hand/manus specimen MSM-303-2 was collected from mid Bor. It is best preserved with its some elements articulated and some elements have impressions (Figure 4). The manus is tridactyl. Manus/hand has thick bones. The digit I has carpal, metacarpal I (robust), phalanx I, and hand ungual I/claw I/toe I (Figure 4). The digit II has preserved carpal, metacarpal II, phalange II-1, phalange II-II and possibly ungual II/claw II/toe II). This ungual/claw II is found in the matrix (Figure 4). The digit III has bones and impression of bones like carpal, metacarpal III, phalange III-I, phalange III-II, phalange III-III and ungual III or claw III or toe III. Only one phalange is preserved in the relevant digit III row while other phalanges, toes and carpal found in the matrix just below the digit 1 (Figure 4) and also may be in the matrix. The metacarpal III impression is preserved. The sample preparation will clear the remaining elements. The carpal I is anteroposteriorly thin plate and has anterior concavity. The metacarpal I is the smallest while Metacarpal II is largest (Figure 4) and metacarpal III is relatively intermediate (Figure 4). The metacarpal $I$ is expanded at proximal and distal ends while in the middle it seems to be constricted (Figure 4). The metacarpal II is the longest and also thickest (Figure 4) but middle constriction is not clear. The metacarpal III is intermediate in length and also in thickness than metacarpal I and metacarpal II. The width of metacarpal I is about $7 \mathrm{~mm}$ (millimeter) while length is about $21 \mathrm{~mm}$. 
The phalanges are robust and elongated having expanded articular surfaces/condyles (Figure 4). The width of phalange of digit I is about $7 \mathrm{~mm}$ while length is about $21 \mathrm{~mm}$ (Figure 4). The manus elements were preserved in articulation with their position in the foot and provide the possible Phalangeal formula for Vitakrisaurus saraiki.

The possible manual Phalangeal formula 1-2-3 including manual ungual/claw/ toe formula 1-1-1. The central digit (digit II) is longest and also broadest while the left digit (digit I) is short or reduced than other digit II and digit III (Figure 4).

The right digit (digit III) is intermediate than other digit I and digit II. It means the digit III is smaller than digit II and longer than digit I (Figure 4). The phalange of digit I is elongated. The phalanges of digit II are relatively less elongated. Phalanges of digit III are short and also expected short recurved claw. The non-ungual phalanges have expanded proximal articulation and concave nature while the distal articulation is ginglymoid, with separated condyles, although there is variation in shape.

The ungual/claw of manus is robust. Manual ungual or claw I is thick, robust and slightly recurved downward. The ungual/claw I is three time long than its transverse width and also ventrodorsal height (Figure 4). The thickness and width of claw is becoming less toward posteriorly and show a rounded asymmetrical recurved nature (Figure 4). The ungual phalange is curved, with their tips projected well beneath the base of the proximal articulation (Figure 4) but not as raptorial as in later theropods [44]. Manus elements are robust in Vitakrisaurus (Figure 4) than oviraptorid Khaan [45] [46] which have slender manus elements.

\section{Mesoeucrocodiles from the Latest Maastrichtian Vitakri Formation of Pakistan}

From India isolated teeth and vertebrae were reported by many authors [47] but these are not diagnostic upto lower level of Mesoeucrodiles. From Pakistan three diagnostic mesoeucrocodiles (Figures 7-12) are known like Pabwehshi pakistanensis [47] attributed on cranial materials (Figure 12), Induszalim bala based on cranial and postcranial materials (Figures 7-11) and Sulaimanisuchus kinwai also based on cranial and postcranial materials (Figure 12) found from Pakistan. Here the description of Induszalim bala and Sulaimanisuchus kinwai along with large photographs/photos of their fossils and comparison with Pabwehshi pakistanensis and some other mesoeucrocodiles are presented.

\subsection{Induszalim bala Mesoeucrocodile from Pakistan}

Systematic paleontology of Induszalim bala is as follows.

$$
\begin{aligned}
& \text { Crocodyliformes [48]; } \\
& \text { Mesoeucrocodylia [49]; } \\
& \text { Induszalimidae [50]; } \\
& \text { Induszalim [15] [50]; }
\end{aligned}
$$


Induszalim bala [15] [50];

(Figures 7-11).

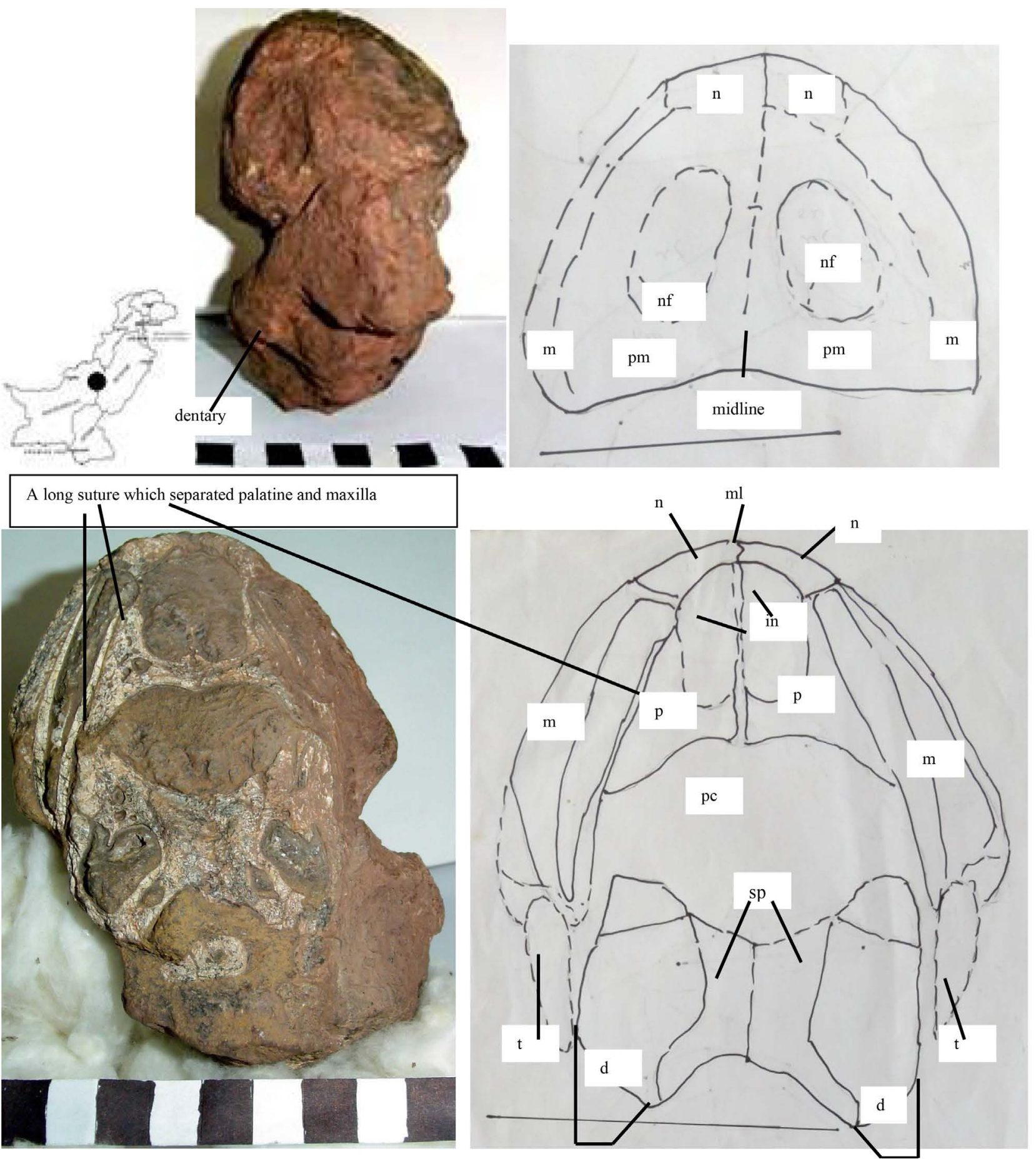

Figure 7. Induszalim bala holotype (in Figures 7-10). Map of Pakistan show type locality Alam 19 (black circle) of holotypic skeleton of Induszalim bala mesoeucrocodile, Barkhan district, Balochistan; images and line drawings of Induszalim bala holotypic rostrum or snout MSM-155-19 (=MSM-55-19c due to central Alam) in anterior view (row 1) and posterior cross sectional view (row 2). The dentary symphysis is articulated but not drawn. Scale, each black or white digit is $1 \mathrm{~cm}$ in image. The scale bar in line drawing is $5 \mathrm{~cm}$. Abbreviations: $\mathrm{d}$, dentary ramus; en, external naris; in, internal naris; $\mathrm{m}$, maxilla; ml, midline contact; $\mathrm{n}$, nasal; $\mathrm{nf}$, narial fossa including the external naris covered by muddy matrix; $p$, palatal process; pc, palatal cavity; pm, premaxilla; sp, splenial; t, tooth. 


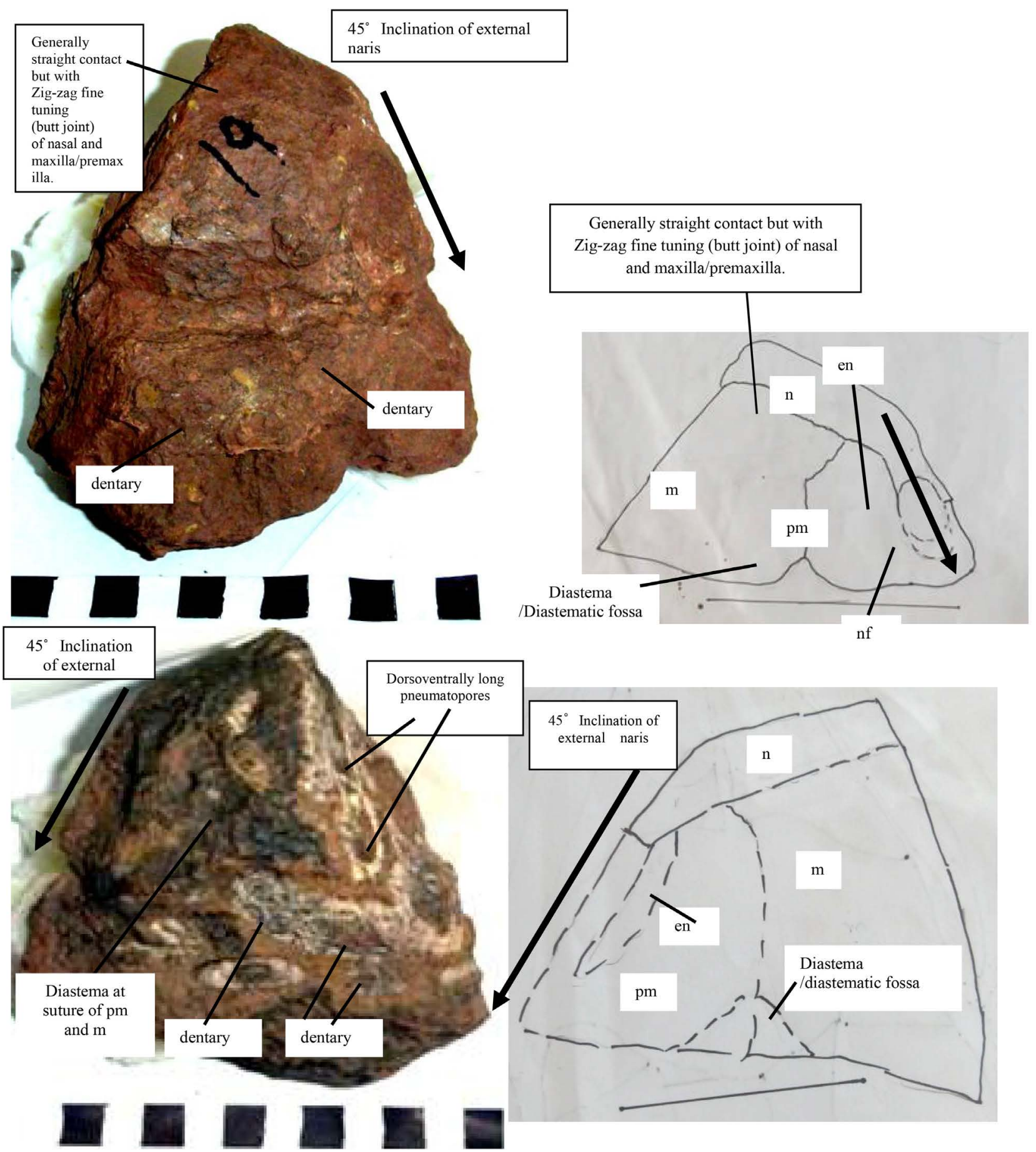

Figure 8. Induszalim bala holotype (in Figures 7-10). Rows 1 and 2, Images and line drawings of Induszalim bala holotypic rostrum MSM-155-19 in right and left lateral views. The dentary symphysis is articulated but not drawn. Scale, each black or white digit is $1 \mathrm{~cm}$ in image. The scale bar in line drawing is $5 \mathrm{~cm}$. Abbreviations: en, external naris; $\mathrm{m}$, maxilla; $\mathrm{n}$, nasal; nf, narial fossa including the external naris covered by muddy matrix; pm, premaxilla. Arrow shows $45^{\circ}$ inclination of external naris.

Induszalim bala holotypic rostrum MSM-155-19 and caudal vertebrae, humeri, ulna, distal femur, metatarsals and metacarpals, and articulated tibia and fibula (Figures 7-10) from Alam 19 type locality, and referred snout GSP/MSM-4-3 (Figure 11) and dentary ramus GSP/MSM-5-3 (Figure 11) found from Shalghara 3 
locality, dentary ramus articulated with four teeth (Figure 11) found from mid Bor 2 locality, and a dorsal vertebra (Figure 11) from Mari Bohri 15 found
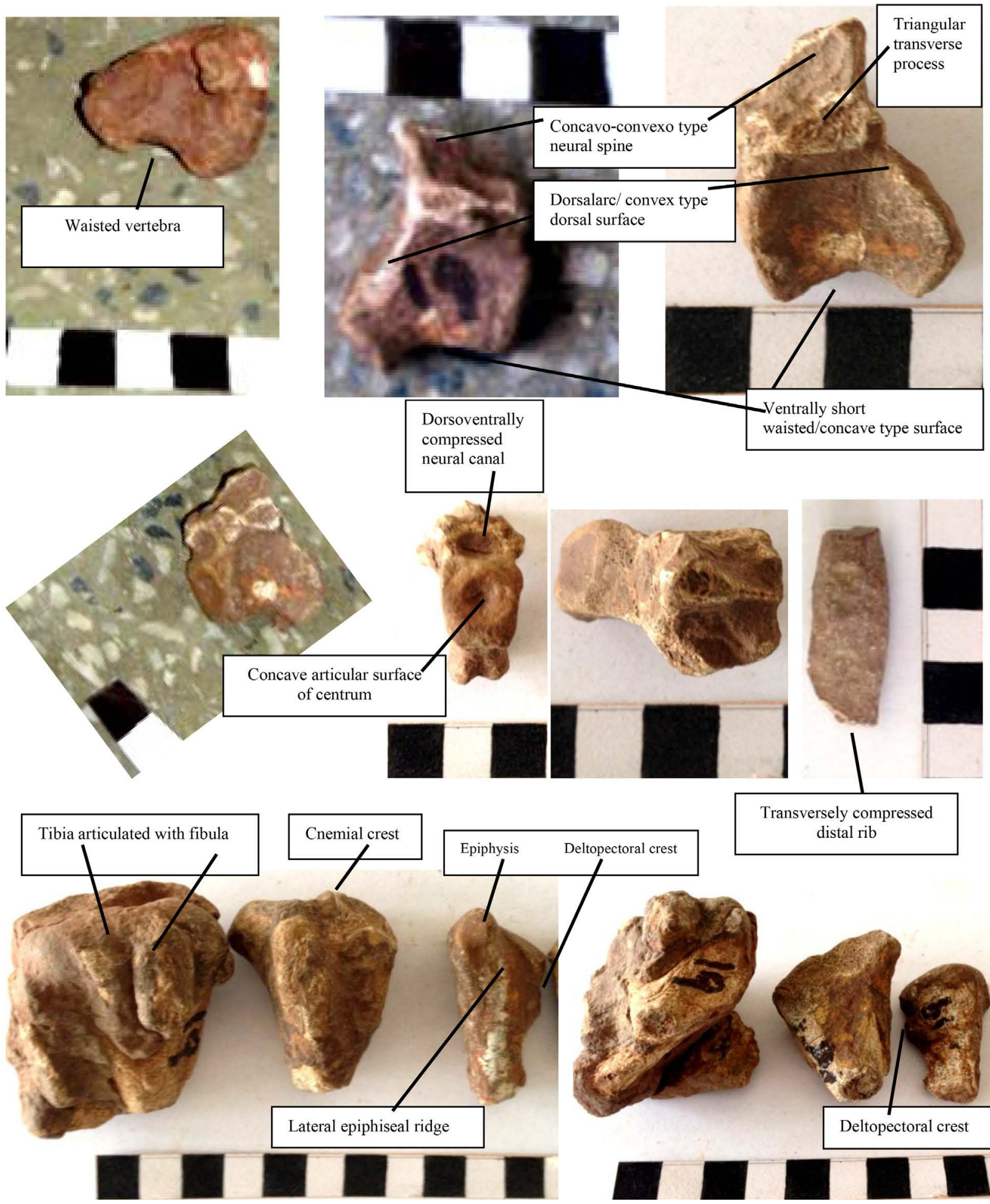

Transversely compressed distal rib

Figure 9. Induszalim bala holotype (in Figures 7-10). Row 1, caudal vertebra MSM-1084-19; caudal vertebra MSM-65-19 in 2 views. Row 2, caudal vertebra MSM-65-19 in 3 views; distal rib MSM-1085-19. Row 3, proximal left tibia articulated with proximal left fibula MSM-1086-19, proximal left ulna MSM-1086-19 and proximal left humerus MSM-1087-19 in 2 views. Scale, every black/white digit is $1 \mathrm{~cm}$. 

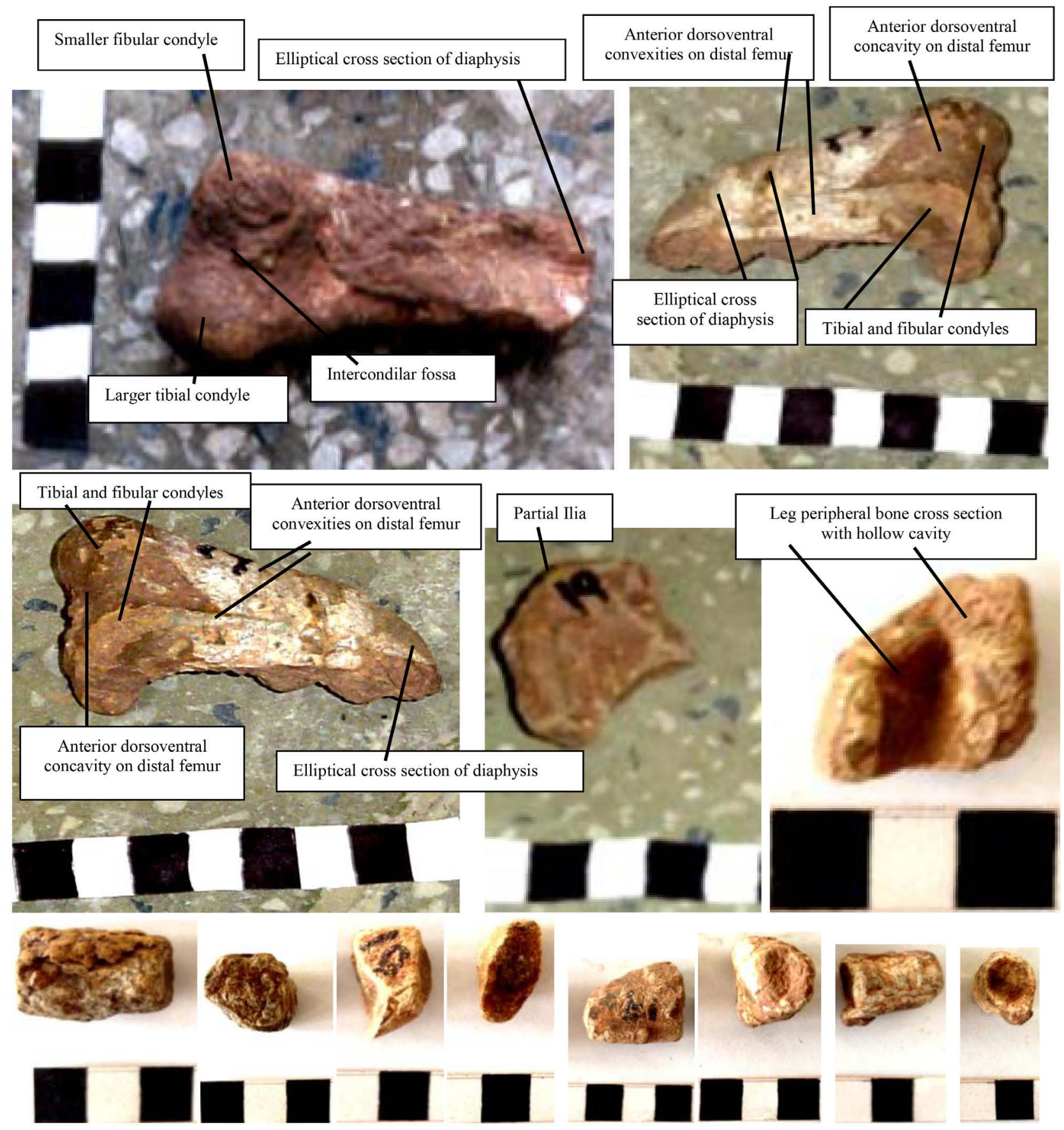

Figure 10. Induszalim bala holotypic fossils (in Figures 7-10). Row 1, distal and mid left femur MSM-66-19 in 2 views, Row 2, distal and mid left femur MSM-66-19; ilium MSM-1088-19 and limb bone cross section MSM-1093-19. Row 3, metacarpals/metatarsals dorsoventrally compressed MSM-1089-19 in ventral and cross sectional views; MSM-1090-19 in ventral and cross sectional views; MSM-1091-19 in dorsal and cross sectional views; MSM-1092-19 in ventral and cross sectional views. Scale, each black or white digit is $1 \mathrm{~cm}$.

in latest Maastrichtian Vitakri Formation of Fort Munro Group, Barkhan District, Balochistan Province, central Pakistan. Further three articulated vertebrae GSP/MSM-9-3 and one distal humerus/femur MSM-10-3 of mesoeucrocodiles found from Shalghara locality, and one simple armor plate or osteoderm 


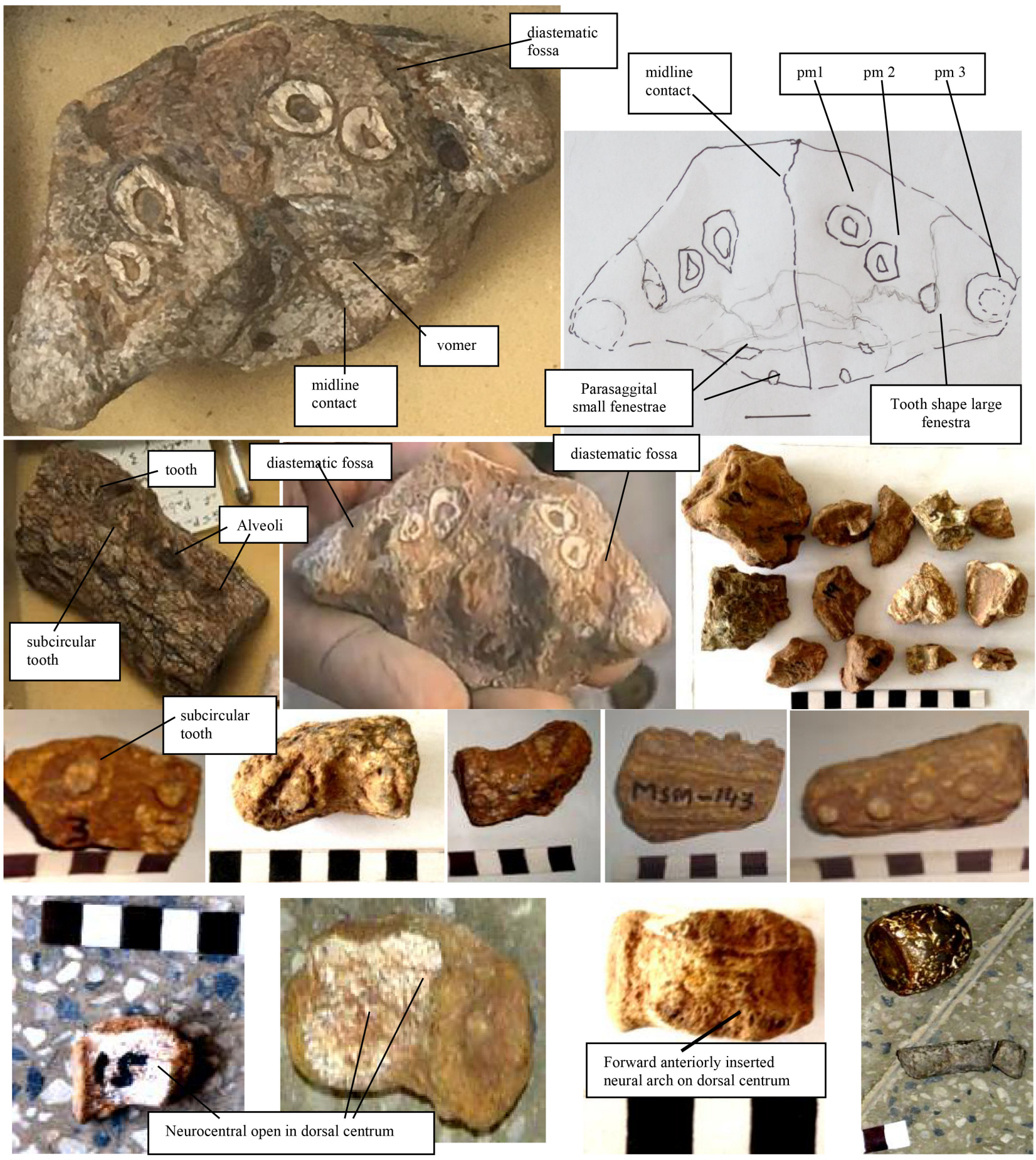

Figure 11. Induszalim bala referred fossils. Row 1, image and line drawings of snout GSP/MSM-4-3 [58] found and collected by present author from Shalghara locality. Row 2, p1, dentary ramus GSP/MSM-5-3 [58] found and collected by present author from Shalghara; p2, snout GSP/MSM-4-3 found from Shalghara 3 locality; p3, some mixed cranial and postcranial fossils of mesoeucrocodiles/titanosaurs/theropods /pterosaurs found from Alam and other localities. Row 3, right jaw ramus with 2 teeth having sandwiched diastema and diastematic fossa MSM-139-3 found from Shalghara in 3 views; dentary/jaw ramus with teeth MSM-143-2 from Bor locality in 2 views. Row 4, p1, p2, p3, dorsal vertebra MSM-64-15 in 3 views; and p4, possible egg MSM-1058-K (may belong to turtle or crocodile; upper) found from about 5 - $8 \mathrm{~km}$ east of Karkh town of Khuzdar district, and partial rib or phalanges MSM-1057-K (lower) found from south of Khuzdar town and road. Scale, each black or white digit is $1 \mathrm{~cm}$. Scale bar in line drawing is about $1 \mathrm{~cm}$. 
MSM-8-3 of titanosaur were received by Dr David Krauss, Bostan College, USA from GSP for preparation since 2001. These three articulated vertebrae and one femur of mesoeucrocodiles matches closely with Induszalim vertebrae and femur that is the reason for referring to Induszalim bala. All these holotypic and referred fossils were discovered by the present author. The explanation of referring is mentioned in description. Fossils are housed in the museum of Geological Survey of Pakistan, Quetta. Initially the holotypic rostrum MSM-155-19 was part of holotype of Vitakridrinda theropod [51]. The Genus name Induszalim is after Indus River of Pakistan and Zalim is Urdu and Saraiki word meaning cruel, and species name $I$. bala is after Saraiki word bala mean big terrible animal.

\subsubsection{Diagnosis of Induszalim bala Mesoeucrocodile from Pakistan}

Crocodiles are commonly recognized on teeth morphology and orientation and patter and variations in mandible and jaw bones and morphology of skull, etc. Fortunately from Pakistan three diverse and distinct teeth morphology and their occurrences are recognized in Induszalim, Pabwehshi and Sulaimanisuchus. Induszalim bala secondary plate, butt suture lines and age shared with mesoeucrocodiles. Induszalim bala (and also Pabwehshi pakistanensis) medium sized crocodyliform sharing with the Induszalimidae as a reduced anterior portion of the rostrum retaining only three premaxillary teeth; diastematic fossa positioned just posterior to the second maxillary tooth; a prominent premaxillary lip overhanging the external nares, high and deep snout, maximum depth of snout is $3 / 4$ of maximum width, symmetrical horizontal sagital torus of palatine bone and splenial contact all along the dentary. The Induszalim and Pabwehshi have a sagital torus on its maxillary palatal shelves and third premaxillary circular tooth which is not reported in baurusuchids [52]. So both Pabwehshi and Induszalim belong to Induszalimidae. Induszalimidae based on Induszalim bala genus and species.

Induszalim bala is characterized by the following autapomorphies. Induszalim bala medium sized crocodyliform has third premaxillary circular tooth (Figure 11) while the Baurusuchus Baurusuchid has third premaxillary enlarged and transversely strongly compressed tooth. Induszalim bala has first premaxillary alveolus and tooth on the jaw axis (Figure 11), while Pabwehshi has a dorsally inset first premaxillary alveolus (Figure 12). Induszalim bala has first premaxillary circular/subcircular tooth (Figure 11), while Pabwehshi has strongly transversely compressed first premaxillary tooth (Figure 12). Induszalim bala has second premaxillary asymmetric D-shaped tooth with plain side is slightly concave and other side is asymmetrical convexing (Figure 11), while Pabwehshi has strongly transversely compressed oval second premaxillary tooth (Figure 12). Induszalim bala has third premaxillary circular tooth (Figure 11), while Pabwehshi has strongly transversely compressed oval third premaxillary tooth (Figure 12). Induszalim bala has one large D-shaped fenestra between the second and third premaxillary teeth which may accommodate the third dentary 
tooth (Figure 11), while Pabwehshi has a large fenestra but medially oriented and off set from teeth axis [47]. Induszalim bala has a diastematic fossa just lateral to a large D-shaped fenestra between the second and third premaxillary teeth (Figure 11) which is trended anterolaterally, while Pabwehshi has a large fenestra but medially oriented and off set from teeth axis [47]. Induszalim bala has subrectangle shaped vomer (Figure 11). Induszalim bala has two pair of relatively small parasaggital fenestrae located between the jaw axis and mid line, however one pair of fenestra is just close to midline (Figure 11), while Pabwehshi has only a pair of large fenestra. Induszalim bala has maxillary diastematic fossa probably between maxillary second and third teeth for the accommodation of possibly large dentary tooth 6 . Induszalim bony secondary plate is formed by premaxilla, maxilla and palatine, while Pabwehshi secondary plate is formed by premaxilla and maxilla only. External nare is sub terminal. Anterior rostrum is moderately inclined, while it is vertical in Pabwehshi. Stepped premaxilla strip has found anterior to narial fossa, while Pabwehshi have no step. Induszalim has twice deep palatal cavity than Pabwehshi. In Induszalim the suture of nasal with premaxilla and maxilla is generally straight line with fine zigzag butt suture. The contact of maxilla and premaxilla is butt and wavy line. Splenial and dentary are united as concavo-convexo style with axis in mid while its axis is shifted ventrally in Pabwehshi. In Induszalim the diverticulum in wall of internal naris is negligible while diverticulum is well developed in Pabwehshi. Tooth bearing maxillary ramus is twice away from internal naris cavity in Induszalim than Pabwehshi. Dorsoventrally oriented elongated large pneumatopores are found in maxilla. Dentary is thick with large pneumatopores in Induszalim while small pneumatopores in Pabwehshi dentary. Induszalim has relatively small internal naris cavity than Pabwehshi. In Induszalim the palatine ramus show elongated contact with maxilla while not found in Pabwehshi. Neurocentral straight suture is open in dorsal centrum. Caudal centra are strongly waisted. Humerus has dorsoventrally elongated oval shaped proximal epiphysis and a prominent lateral ridge continued from epiphysis to downward in Induszalim, while epiphysis is subcircular in Sulaimanisuchus kinwai. Humerus has prominent lateral ridge started from proximal epiphysis to run downward to midshaft, while this lateral ridge is feeble in Sulaimanisuchus kinwai. Ulna is proximally expanded and has prominent olecranon process. Femoral shaft is elliptical. Tibia is flattened type, transversely compressed and has laterally directed cnemial crest. The fibula is strip or belt like, elongated anteroposteriorly and transversely compressed. Metapodials (metacarpals and metatarsals) are broad to strongly broad with central hollow cavity.

\subsubsection{Description of Fossils of Induszalim bala Mesoeucrocodile}

Three mesoeucrocodiles are recognised from Indo-Pakistan subcontinent based on dentition and cranial fossils. The first recognised mesoeucrocodile is Induszalim bala which have circular to subcircular, D-shaped and arced and oval shaped 
teeth with slight transverse compression. The second recognised mesoeucrocodile is Sulaimanisuchus kinwai which have moderately transversely compressed teeth with a few circular to subcircular, D-shaped and oval shaped teeth. The third recognised mesoeucrocodile is Pabwehshi pakistanensis which have strongly compressed teeth (transversely compressed) oval shaped teeth.

Snout, Jaw and Dentary Ramus from Shalghara and Dentary Ramus from Bor: The outer profile and in general the snout GSP/MSM-4-3 (Figure 11) from Shalghara was matching in morphology with the holotypic snouts of Induszalim bala (Figure 7) (Figure 8) and Pabwehshi pakistanensis. Further the slightly compressed teeth on left lateral side of rostrum (Figure 8) provided criteria for referral of this snout to Induszalim, but it is possible that these possible teeth may be pneumatic marks on dentary or dentary fragments. But the teeth size, shape and occurrence pattern of snout GSP/MSM-4-3 (Figure 11) are strongly contrasted from Pabwehshi pakistanensis holotypic snout. Further the snout GSP/MSM-4-3 (Figure 11) with teeth features and compression is different than Sulaimanisuchus kinwai snout MSM-140-3 (Figure 12). So snout GSP/MSM-4-3 is referred to Induszalim bala. Further the snout GSP/MSM-4-3 teeth features especially circular or subcircular or negligible or slight transverse compressed teeth matches with the teeth of dentary ramus (with four spaced teeth) GSP/ MSM-5-3 (Figure 11) and jaw fragment (having two teeth sandwiched with diastema) MSM-139-3 (Figure 11). This is the reason the dentary ramus GSP/ MSM-5-3 and jaw fragment MSM-139-3 are being referred to Induszalim bala. Because the Pabwehshi [47] has strongly compressed oval shaped teeth.

Induszalim bala shows anterodorsally directed external nares (Figure 7) (Figure 8) high/deep and narrow rostrum (Figure 7), the circular or subcircular teeth with no compression or slight compression, asymmetric D-shaped arced teeth with lateroposterior side concave and anteromedial side is convex (Figure 11). Induszalim bala has non-compressed or slightly compressed teeth (Figure 11), while Sulaimanisuchus has moderately compressed teeth (Figure 12), and Pabwehshi has strongly compressed teeth (Figure 12). Induszalim bala has asymmetric concavo-convexo arced teeth (Figure 11), while Sulaimanisuchus and Pabwehshi has no any teeth like this (Figure 11). Induszalim bala has reduced premaxilla with only three teeth. The first premaxillary tooth in snout GSP/MSM-4-3 is about $8 \mathrm{~mm}$ long anteroposteriorly and $7 \mathrm{~mm}$ wide transversely, the second premaxillary tooth is about $7 \mathrm{~mm}$ long anteroposteriorly and $6 \mathrm{~mm}$ wide transversely and third premaxillary tooth is almost equal to size and shape with first premaxillary tooth. The dentary ramus GSP/MSM-5-3 has about 4 teeth/alveoli (Figure 11). One tooth of dentary ramus GSP/MSM-5-3 is D-shaped and arced like the referred snout GSP/MSM-4-3, the second preserved tooth of has about $1 \mathrm{~cm}$ diameter and other two teeth are relatively small but seem to be circular/subcircular (Figure 11). The dentary ramus GSP/MSM-5-3 teeth nature closely resemble to snout GSP/MSM-4-3. The jaw ramus MSM139-3 from Shalghara locality consists of two teeth sandwiched between a di- 
astematic fossa (Figure 11). Its one tooth is $7 \mathrm{~mm}$ long and $6 \mathrm{~mm}$ wide and it's another tooth is $5 \mathrm{~mm}$ long and $4 \mathrm{~mm}$ wide. Both these teeth are separated by a well developed diastematic fossa (Figure 11). These jaw ramus with two teeth and intercalated diastematic fossa show affinity to snout GSP/MSM-4-3. The teeth nature and diastematic fossa of jaw ramus GSP/MSM-139-3 shows same taxon of snout GSP/MSM-4-3. Like this the dentary ramus GSP/MSM-143-2 from Bor locality shows spaced and circular to subcircular large 3 teeth and distal one relatively small tooth. Its large 3 teeth are $7 \mathrm{~mm}$ long and $5.5 \mathrm{~mm}$ wide and one small tooth which is $6 \mathrm{~mm}$ long and $4.5 \mathrm{~mm}$ wide (Figure 11). This dentary ramus with teeth MSM-143-2 may shows affinity to the snout GSP/ MSM-4-3 taxon. From this it is clear that the snout GSP/MSM-4-3 and dentary ramus GSP/MSM-5-3, and jaw ramus with two teeth interbedded with diastematic fossa MSM-139-3 from Shalghara locality and dentary ramus with 4 teeth MSM-143-2 from Bor locality show that all these may belongs to same taxon of mesoeucrocodile.

The first premaxillary tooth is circular to subcircular in Induszalim (Figure 11), while the first premaxillary tooth in Pabwehshi is strongly transversely compressed (Figure 12). The first premaxillary tooth is oriented on jaw axis in Induszalim (Figure 11), while it is off set from jaw axis in Pabwehshi. The second premaxillary teeth are asymmetric D-shaped arced (lateroposteriorly slightly concave and anteromedially convex) in Induszalim, while the second premaxillary tooth in Pabwehshi is strongly transversely compressed. In Induszalim the first and third premaxillary tooth are relatively large than premaxillary tooth second. In Induszalim, the size of teeth from premaxillary tooth 1 to tooth 2 decreasing and then again increases to premaxillary tooth 3 . While in contrast in Pabwehshi the size of teeth from premaxillary tooth 1 to tooth 3 is increasing. The anterolaterally oblique fenestra seems to be found between the premaxillary tooth 2 and tooth 3 in Induszalim, while it is trended laterally between the premaxillary tooth 2 and tooth 3 in Pabwehshi. The one preserved maxillary tooth is large and circular to subcircular like premaxillary third tooth, and another tooth is arced asymmetric D-shaped with one side slightly concave and other side is convex like premaxillary second tooth. Both these maxillary teeth are separated by diastematic fossa. The posterior maxillary and posterior dentary teeth are relatively small and relatively more spaced than premaxillary teeth (Figure 11). Induszalim has two sagital pair of relatively small fenestra on palatal which is relatively close to mid line (Figure 11), while Pabwehshi has relatively large and away from mid line. One pair of small fenestra is found close to midline while second pair is relative away from midline (Figure 11). The vomer is subrectangular shaped and located on midline. These fossils show two diastematic fossae in jaws for the adjustment of opposite ramus large two teeth.

Rostrum/Snout articulated with dentary symphysis from Alam: The rostrum/snout MSM-155-19 is ornamented with pitted and sculptured grooves and ridges that are distributed most densely on the lateral side of left dentary 
and also on maxilla. These sculptures are mostly found as anteroposteriorly elongate, discontinuous, pitted, rope like structure especially on the maxilla and nasal (Figure 8). This rostrum is D-shaped at cross section. The height of the rostrum is 3/4 (three-quarters) its width (Figure 7) like Pabwehshi. Toward the tip of the rostrum, these dimensions are nearly same. In Induszalim the external nares are sub terminal and not terminal (Figure 7) (Figure 8) while in Pabwehshi [47] it is terminal. The external narial fossa faces anterolaterally and laterodorsally. The external naris bordered anteroventrally by a broad, smooth fossa which is ventrally bounded by an elevated strip of premaxilla (Figure 7). This elevated premaxillary strip is found in Induszalim, while it is not found in Pabwehshi. The rostrum has many small and large internal pneumatic cavities.

The premaxilla is sub-quadrangular in left lateral and right lateral views (Figure 8). It contacts with nasal posterodorsally and the maxilla posteriorly. The premaxilla and nasal enclose the external nares. The nasal forms the posterodorsal margin of external nares (Figure 8), and dorsal and some lateral margin of internal naris upto the available cross section of snout. The premaxilla forms the lateral and ventral wall and anterior and mid parts of dorsal premaxillary lip of external naris. Laterally the suture of maxilla and premaxilla is a butt joint (Figure 8). Dorsally the premaxillae contact with each other to form the midline contact and forms the lip which inclined at about $45^{\circ}$ in Induszalim, while in Pabwehshi it is terminal. This preserved premaxillary lip forms more than $3 / 5$ of anteroposterior length of dorsal roof of external nares. Ventrally, the premaxillae may contact one another at the midline to form the anterior portion of the secondary palate. A diastema is found on the contact of maxilla and premaxilla (Figure 8).

The preserved anterior maxilla is sub-quadrangular/sub rectangular in lateral views (Figure 8). The maxilla and premaxilla form side wall of rostrum (Figure 8). The palatine is separated bones from maxilla and has a well developed contact line (Figure 8). In Induszalim the palatine torus have elongated contact with the maxilla (Figure 8). It represents that secondary palate formed by separate bones in Induszalim, while the palatine and maxilla contact is not distinguished in Pabwehshi which revealed maxilla formed the secondary palate. Dorsally the maxilla meets with nasal forming contact subparallel to midline (with zig-zag fine tuning) in the anterior portion while non-parallel in the posterior part (Figure 8). The maxilla, nasal and palatine bones enclose the internal naris (Figure 8). The nasal forms the dorsal and some dorsolateral margin of internal naris (observed at the available cross section of snout). Laterally the upper half of internal naris is bounded by maxilla while lower half of internal naris is bounded by palatine. The maxilla has a small anterodorsal process but it seems that it does not participate in the boarder of external naris. A prominent and exceptionally very large elongated internal coel (dorsoventrally elongated) is found in the maxilla (observed on posterior view of available cross section). The outer surface of maxilla show some rugose, pitted and anteroposteriorly aligned discontinuous 
lineations (Figure 8).

The belt/strap like nasal forms the roof of rostrum (Figure 7) (Figure 8). It is mostly flat/straight with rugose surface texture. The nasals formed a posterodorsal or distal part of internarial lip. The nasals contact with maxilla as butt or zig-zag type contact. In general this butt contact line is straight (with fine tuning of zig-zag structures) in the anterior part of butt contact in Induszalim, while this contact line is open wavy or open folded (with fine tuning of zig-zag structures) structures in the Pabwehshi. Open folded structure means low dip syncline and anticline. The nasals are slightly arched posteriorly and also anteriorly in Induszalim, while the nasals are slightly arched posteriorly but nearly flat anteriorly in Pabwehshi. The Induszalim nasals form the upper two fifth of the margin of the narial fossa as well as a two fifth portion of its overhanging lip, while the Pabwehshi nasals form the upper one-third of the margin of the external naris as well as a small portion of its overhanging lip [47]. The lower portion of internarial bar is clearly formed by palatine while mid portion is slightly preserved and tilted right side (of observing man) and dorsal portion of internarial bar is damaged. Internal bar is separated bilaminae (Figure 7).

The dentary symphysis is preserved in interlocking with maxilla and premaxilla (Figure 7). The both rami of dentary also articulated with the relevant splenial. The exposed left lateral dentary shows rugose and pitted surfaces, some of which are aligned anteroposteriorly and some are random. The right and left dentary rami have a large and some small internal cells/cavity and some found in the central part of dentary (Figure 7). The splenial joined with relevant dentary by the concave structure while the dentary have convex structure to fit the suture (Figure 7). The splenial contacts the medial aspect of the dentary along its height from the base of the jaw ramus to alveolar margin by concavo-convexo style (Figure 7). The axis of concavo-convexo shaped joint is found in the dorsoventrally centre of bones in Induszalim, while its axis is shifted downward (close to ventral portion) in the Pabwehshi (Figure 7). Further thick and deep dentary ramus with subcircular to D-shaped teeth and alveoli found from Sangiali locality 3 is being referred to Induszalim bala (Figure 11). Only the portion of the splenial is being observed at the preserved cross sectional view (Figure 7). The general shape of the splenial observed at cross section is thick robust four limbs X shaped or four rayed star shaped. The two limbs with concave shaped join the dentary while medially formed vertical straight mid contact. Splenial extends medially to the midline and participates in the symphysis. Splenial contacts the medial aspect of the dentary along its height from the base of the jaw ramus to the alveolar margin. The splenial bones are relatively more massive than dentary i.e. there are small pores in the splenial while dentary have coarse spongy pores. Splenial have relatively small subcircular, elongated to lense type spongy cavities. Splenial form a significant part of symphysis, it is robust, however lateromedial width is significantly less than dorsoventral width (Figure 7). The dorsoventral depth of both fellow of splenial is more than the transverse 
width (Figure 7).

The ventral and dorsal surfaces of each fellow of palatines are concave which meet on midline formed secondary plate. Palatine covers the ventral and lower half of lateral part of internal naris. The upper half of internal naris is laterally mostly bounded by maxilla and dorsal part of internal naris is capped by slightly concave nasal. The Induszalim (like Pabwehshi) have sagital torus on palatal shelves (Figure 7) while baurusuchids have no sagital torus. The reference [53] mentioned that 'the intermediate 'mesosuchian' crocodilians were common during the Jurassic and Cretaceous and were characterized by a bony secondary palate composed of premaxillae, maxillae, and palatines, among other features" and this statement is true for Induszalim but not for Pabwehshi. The Pabwehshi follows the [54] statement that "a bony secondary palate formed by these same two bones the premaxilla and maxilla" while Induszalim did not follow this.

One dorsal vertebra (Figure 11) and two caudal vertebrae (Figure 9) are described here. One dorsal centrum from Mari Bohri 15 is referred to Induszalim due to size and same horizon. The dorsal centrum (Figure 11) is relatively robust, thick and big in size than caudal vertebrae. Its centrum is long, slightly tall and slightly waisted. Its width is $1.7 \mathrm{~cm}$, height is $1.9 \mathrm{~cm}$ and length is $2.9 \mathrm{~cm}$. The anterior and posterior articular surfaces of centrum are amphicoelous. The joint of neural arch and dorsal centrum cover most of the dorsal surface while in caudal vertebrae the neural arch is found in the anterior and mid part of dorsal aspect of centrum. The neurocentral suture opens (Figure 11) in dorsal vertebrae of Induszalim bala. The neurocentral suture line found on the lateral side of centra is generally straight (Figure 11) in Induszalim while it is wavy in dorsal vertebrae of Campinasuchus dinizi [55]. A partial distal rib $3 \mathrm{~cm}$ long and more than $1 \mathrm{~cm}$ wide is preserved in the holotypic materials. It is strip and belt like slightly tapering to distal ends. This rib is transversely compressed and anteroposteriorly elongated. This holotypic rib of Induszalim bala matches with the holotypic rib of Khuzdarcroco zahri [15] found from Khuzdar. This is the reason the Khuzdarcroco zahri rib is here being referred to Induszalim bala. The referred mid rib is belt like slightly recurved and seems to be massive (Figure 11). This preserved partial mid rib length is $6 \mathrm{~cm}$, width is $2.5 \mathrm{~cm}$ and depth is $1 \mathrm{~cm}$ (Figure 11).

The caudal vertebrae (Figure 9) are long, waisted and arced. Its centra are long and highly strongly waisted. The centra formed the arc shape on lateral view; the ventral view is concave while the dorsal surface is convex. The anteroposterior length of ventral view of centrum is $2 / 3$ of anteroposterior length of dorsal view. In this way the dorsal length is significantly more than ventral length. Further the anterior and posterior articular surfaces are not equal. The anterior articular surface or ring is larger than posterior articular ring. This vertebra has anterior prezygapophyses. Some parts of postzygapophysis and neural spine are preserved. Neural spine is slightly directed posteriorly. Neural spine is broad transversely. The neural spine is concave anteriorly and convex posterior- 
ly. Neural canal is dorsoventrally compressed and transversely elongated oval shaped. Its transverse process is triangular. Its centrum MSM-65-19 width is 1.3 $\mathrm{cm}$, height is $1.5 \mathrm{~cm}$ and length is $2.3 \mathrm{~cm}$. The caudal centra forming arc along with ventral length is highly reduced than dorsal length, triangular transverse process and transversely elongated oval shaped neural canal seem to be autapomorphies of Induszalim.

The proximal humerus (Figure 9) is expanded and very wide in the proximal surface which is more than twice of shaft diaphysis. Its diaphysis is suboval. The deltopectoral crest is laterally directed and prominent. The humerus shaft seems to be straight. The humerus proximal epiphysis is dorsoventrally long oval shaped (while it is subcircular in Sulaimanisuchus kinwai) and high and inclined lateromedially. An anterior prominent ridge started from proximal epiphysis to travel downward mid shaft. This dorsoventrally oriented anterior ridge is prominent in Induszalim bala (Figure 9), while it is feeble in Sulaimanisuchus kinwai (Figure 12). The transverse width is being reduced to the diaphysis. Cross section of shaft is transversely oval to elliptical and have oval hollow cavity in the centre enveloped by thin peripheral bone (Figure 9). This holotypic humerus of Induszalim bala is different than the holotypic humerus of Sulaimanisuchus kinwai.

The proximal ulna is tri-rays (Figure 9). This is significantly expanded proximally. The proximal extremity of the ulna is more than three times wider than the diaphysis. The cnemial crest is prominent. The preserved cross section of shaft is subtriangular to oval shaped. One side of cross section is thick and another side is thin (Figure 9).

The iliac plate is partially preserved (Figure 10). It is slightly arced and thick plate. On one ventral side, it has the arc type shaped acetabulum for the adjustment of femur head and anteroposterior rotation of femur during locomotion.

The distal femur (Figure 10) shows preserved distal length $7 \mathrm{~cm}$, distal condyles width $3.5 \mathrm{~cm}$ and depth $2.5 \mathrm{~cm}$. The complete femur may be $20 \mathrm{~cm}$ long. The femur is moderately robust and expanded distally. The tibial condyle is greater in size than fibular condyle. The tibial condyle transverse width is $2.6 \mathrm{~cm}$ and depth is about $2 \mathrm{~cm}$ while fibular condyle width is $1.8 \mathrm{~cm}$ and depth is 1.5 $\mathrm{cm}$. Cross section of shaft is elliptical and maximum on the distal condylar part and decreasing proximally. The shaft seems to be slightly curved/sigmoid. The Intercondylar fossa between the fibular and tibial condyle of distal femur is prominent (Figure 10). The prominent dorsoventrally elongated convexities exposed anteriorly on the medial and lateral diaphysis margin (of distal femur) and join the respective tibial and fibular condyles. Induszalim has elliptical femoral shaft like Campinasuchus dinizi [55], while in contrast the Adamantinasuchus navae [56] and Mariliasuchus amarali [57] have oval femoral shaft.

The holotypic proximal tibia (Figure 9) is generally flattened type, transversely compressed and elongated anteroposteriorly. Its anteroposterior length of proximal tibia is strongly more than its transverse width. The cnemial crest is 
laterally directed. Its preserved shaft cross section is elongated anteroposteriorly. The tibia is articulated with fibula (Figure 9). The proximal fibula is strip or belt like, anteroposteriorly elongated and transversely compressed (Figure 9). Fibula has almost same anteroposterior length all along the reserved portion.

The collected metapodials (metacarpals and metatarsals; Figure 10) which are transversely wide and broad to strongly broad, and dorsoventrally compressed (Figure 10) showing planatar or semiplanatar locomotion style. Their cross section shows oval to subcircular hollow cavity in the core which is enveloped by peripheral bone. The metacarpals and metatarsals shaft cross section are thick and long (Figure 10). Any metacarpals/metatarsals collected did not show fused phalanges, revealing that the phalanges are unfused.

Further the egg (Figure 11) collected from late Cretaceous strata of Karkh locality, Khuzdar District, Balochistan (in the western Kirthar Range) is being assigned to a large turtle or crocodile due to its size. The egg (Figure 11) is oval shaped with white thin outer spongy layer and fine muddy amorphous internal core may be preserved after hatching or before the development of infant. The outer shell cover is porous with white and grey colors. Preserved half egg length is $4 \mathrm{~cm}$, diameters are 3.8 and $4.2 \mathrm{~cm}$ (Figure 11).

\subsubsection{Discussion on Induszalim bala and Its Paleobiogeographic Affinity} Induszalim and Pabwehshi have relatively deep rostrum, and divided anterolaterally facing external nares exclude these from Neosuchia, which is characterized by a dorsoventrally compressed rostrum and confluent, dorsally facing external nares [54]. Induszalim and Pabwehshi has a smooth narial fossa surrounding the ventral and lateral portions of the external naris, as in baurusuchids (Baurusuchus), peirosaurids (Peirosaurus, Stolokrosuchus), and Araripesuchus. Chimaerasuchus but differs in this respect from other notosuchids (Notosuchus, Malawisuchus, Simosuchus). The reference [52] mentioned that Pabwehshi has a sagital torus on its maxillary palatal shelves - a character that is absent in baurusuchids.

Induszalim bala ornamentation and sculptures on dentary and external narial position matches closely with Gondwanasuchus scabrosus [59]. Induszalim bala parallel sculptures on dentary matches with Uberabasuchus terrificus [60]. Induszalim bala have subterminal nares with $45^{\circ}$ dorsal profile and in this respect distinct from Pabwehshi pakistanensis [47], Mariliasuchus amarali [57], Caipirasuchus [61] and Montealtosuchus arrudacamposi [62] which have terminal external nares. The position of external nares and $45^{\circ}$ inclination of Induszalim bala matches to Adamantinasuchus navae [55]. Induszalim have more deep rostrum than Morrinhosuchus luziae [63], Baurusuchus salgadoensis [64], Gondwanasuchus scabrosus [59] and many others. Induszalim bala dorsal centrum have neurocentral suture open on lateral view like Campinasuchus dinizi [55]. The neurocentral suture line found on the lateral side of centra is generally straight but with butt type in fine tuning in Induszalim bala while it is wavy in dorsal vertebrae of Campinasuchus dinizi [55]. A partial rib is belt like slightly recurved and seems to be massive. 
Induszalim bala have deep rostrum while Malagasy crocodiles Mahajangasuchus insignis [65]; Simosuchus clarki [66]; Araripesuchus sp. have relatively broad rostrum. Induszalim matches with the Majungatholus atopus [67] on the inclined position of external nares. Induszalim bala have circular or subcircular teeth and differ in this respect from Sebecosuchian which have laterally compressed and very thick teeth [68].

Although basal mesoeucrocodiles are common in Gondwana and rare in Laurasia (Asia, Chimaerasuchus, [69]; Europe, Iberosuchus, [70] [71], Induszalim closely correlated with both Brazilian and Argentinean mesoeucrocodiles and Majungatholus atopus [67] from Madagascar, which revealed the early common seed radiation during Early Cretaceous when these lands united or connected with land bridges. In this way latest Cretaceous mesoeucrocodiles, theropods and titanosaurs showed more affinity to Gondwana lands (Southern Earth), and titanosaurs showed also some affinity to Europe and South America (Laurasia, Northern Earth).

\subsection{Sulaimanisuchus kinwai Mesoeucrocodile from Pakistan}

Sulaimanisuchus kinwai [26] holotypic dentary and associated humerus (Figure 12) found from the latest Maastrichtian (67 - $66 \mathrm{Ma}$ ) Vitakri Formation of Kinwa, Barkhan District, Balochistan. Anteriormost snout (MSM-140-3) (Figure 12) from Shalghara is being referred to Sulaimanisuchus kinwai due to overlapping of moderately compressed teeth (autapomorphy), because Induszalim has mostly non-compressed (autapomorphy) to weakly compressed teeth, and Pabwehshi has mostly strongly compressed teeth (autapomorphy). Sulaimanisuchus kinwai have autapomorhies of moderately compressed teeth, first dentary tooth is small and circular, first mandibular tooth is D-shaped moderately compressed moderate size tooth, subcircular proximal epiphysis and a feeble lateral ridge started from proximal epiphysis to midshaft of humerus (Figure 12). The premaxillary and mandibular teeth show mostly moderately compressed to a few subcircular teeth. Further the first premaxillary tooth of Sulaimanisuchus kinwai is asymmetric moderately compressed oval shaped (anterior side thick and posterior side thin), while in Induszalim the first premaxillary tooth is circular or subcircular, and in Pabwehshi the first premaxillary tooth is highly compressed oval shaped. The mandibular rami symphysis consists of fused dentaries and splenial preserved from their posterior margin at the fifth alveolus forward. This mandible is D shaped arc with less shallow at the anterior part and relatively more deep in the posterior part. Its transverse width is maximum at the position of $\mathrm{d} 4$ (dentary tooth 4 ) and become gradually decreasing toward anterior to $\mathrm{d} 1$ and abruptly decreasing towards posterior to $\mathrm{d} 5$. The first dentary tooth is thin and peg like which is close to mid line. The $\mathrm{d} 2$ and $\mathrm{d} 3$ are relatively thicker than $\mathrm{d} 1$. The $\mathrm{d} 4$ is relatively enlarged and more thick and oval than $\mathrm{d} 1, \mathrm{~d} 2$ and $\mathrm{d} 3$. The $\mathrm{d} 5$ is also enlarged and thicker than $\mathrm{d} 1, \mathrm{~d} 2$ and $\mathrm{d} 3$, and located close to splenial and midline relative to $\mathrm{d} 4$ and $\mathrm{d} 3$. In this way $\mathrm{d} 5$ is off set strongly 


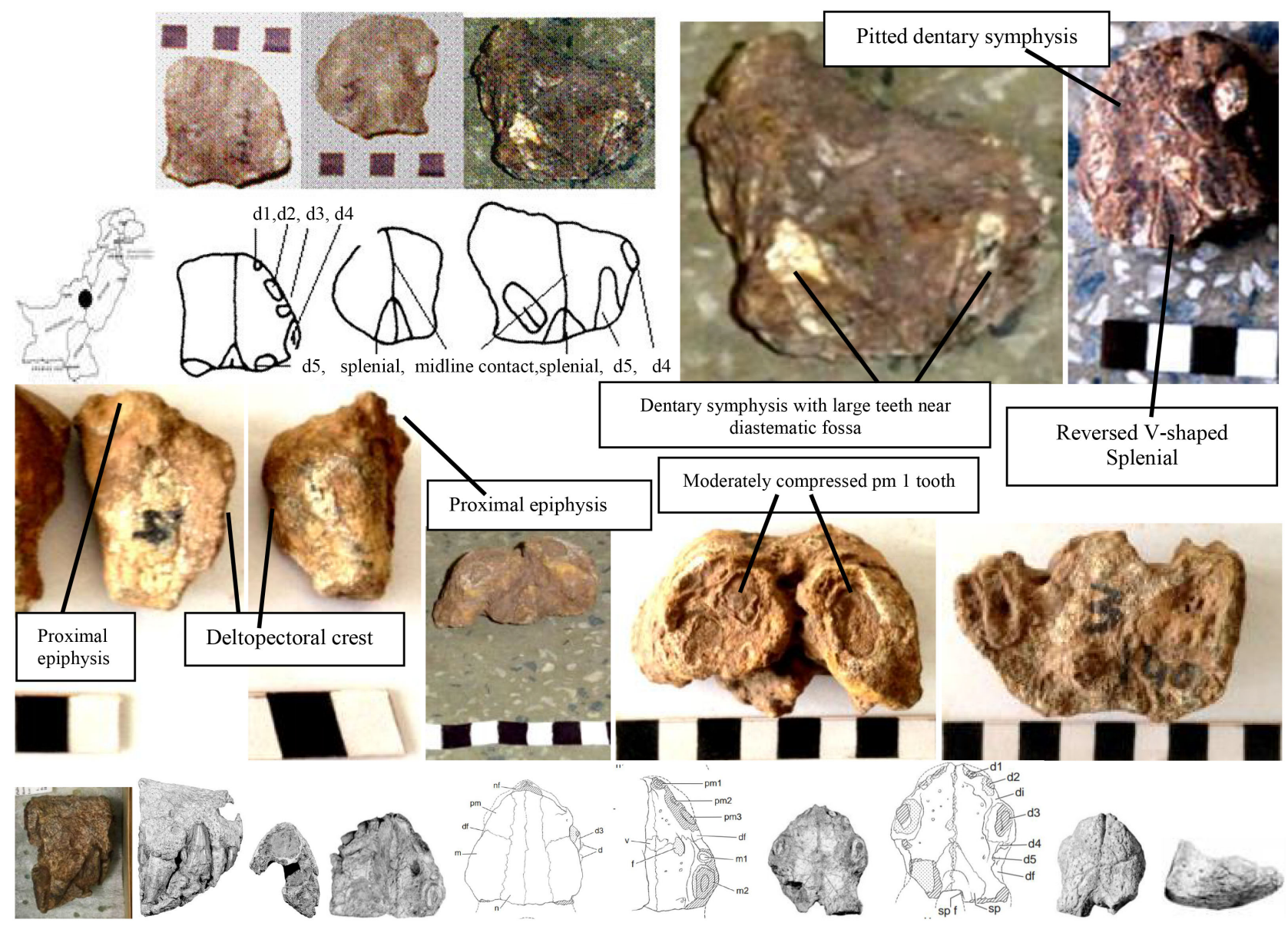

Figure 12. Sulaimanisuchus kinwai holotypic and referred fossils (Rows 1 and 2) and Pabwehshi pakistanensis holotypic and referred fossils (row 3). Row 1, p1, map of Pakistan showing Kinwa 4 or South Kinwa 4s type locality (in black circle), Barkhan District, Balochistan; p2, p3, p4, image (upper) and line drawings (lower) of Sulaimanisuchus kinwai holotypic dentary MSM-63-4 from south Kinwa 4 type locality (in different views); Row 2, p1, p2, Sulaimanisuchus kinwai holotypic proximal humerus MSM-1094-4 found from south Kinwa 4 type locality (in 2 views); p3, p4, p5, Sulaimanisuchus kinwai referred jaw symphysis (anteriormost snout) with 2 alveoli MSM-140-3 found from Shalghara 3 (in 3 views). Row 3, p1-p6, Pabwehshi pakistanensis holotypic rostrum GSP/MSM-3-16 (GSP-UM-2000; [47]) discovered and collected by present author from Top Kinwa 16 locality; p7-10, Pabwehshi pakistanensis referred dentary GSP/MSM-6-3 (GSP-UM-2001; [47]) discovered and collected by present author from Shalghara 3 locality. Scale, each black or white digit is $1 \mathrm{~cm}$. Abbreviations, d1, dentary tooth 1; d2, dentary tooth 2; d3, dentary tooth 3 ; d4, dentary tooth 4 ; $\mathrm{d} 5$, dentary tooth 5 ; di, diastema; df, diastematic fossa; $\mathrm{f}$, foramen; m1, maxillary tooth 1 ; m2, maxillary tooth 2 ; pm1, premaxillary tooth $1 ; \mathrm{pm} 2$, premaxillary tooth 2 ; pm3, premaxillary tooth 3 ; sp, splenial; v, vomer.

medially (autapomorphy). Possible a diastema may be existed between $\mathrm{d} 4$ and $\mathrm{d} 5$ or $\mathrm{d} 5$ and $\mathrm{d} 6$. The arrangement of dentary teeth is different than Induszalim and Pabwehshi. The separation displacement of $\mathrm{d} 1$ and $\mathrm{d} 2$ is slightly more than the inter displacement between other teeth. The portion of splenial anterior to d6 is preserved. The splenial contacts the medial aspects of the dentary along its height from the base of the jaw ramus to the alveolar margin. The splenial extends medially to the midline and participates in the symphysis. Splenial contacts are clear and straight forming $\mathrm{V}$-shaped seen on ventral view. The dentary portion of the mandibular symphysis extends from the back of the mid alveolus of $\mathrm{d} 4$ anteriorly, whereas the splenial makes up the portion from the back of the 
mid alveolus of $\mathrm{d} 4$ posteriorly. Only the first dentary tooth is rounded while remaining most of preserved teeth are moderately compressed oval shaped. The size difference is found in many teeth. The dorsal part of preserved dentary is mostly covered by matrix, however the ventral side is comparatively clean and show pitted surface. The midline contact of splenial and dentary is butt suture type but in general mostly straight (Figure 12). The holotypic proximal humerus (Figure 12) is expanded transversely and very wide in the proximal surface while decreasing toward down forming suboval to oval shape diaphysis. The deltopectoral crest is partially preserved and partially destroyed. The preserved humerus shaft seems to be straight. The humerus proximal epiphysis is located on medial corner. The epiphysis shape is subcircular in Sulaimanisuchus (Figure 12), while it is dorsoventrally long oval shaped in Induszalim (Figure 9). A feeble lateral ridge started from proximal epiphysis of proximal humerus and travel downward upto preserved shaft (Figure 12), while this ridge is prominent in Induszalim bala (Figure 9). Cross section of shaft have oval hollow cavity in the centre enveloped by thin peripheral bone (Figure 12).

\section{Saraikisaurus minhui Pterosaur-the Flying Reptile from the Latest Cretaceous of Indo-Pakistan Subcontinent}

The reference [72] were the first to report jaw fragment of pterosaur in a latest Cretaceous boulder from the latest Cretaceous Lameta sediments [72] [73] of Kotah, Rajasthan, India. Later on [74] [75] reported pterosaurs from lower Jurassic Kota formation of India. Recently [9] reported holotypic dentary ramus (lower beak) with articulated teeth (Figure 13) of Saraikisaurus minhui [9] Saraikisauridae Pterodactyloidea from Pakistan and the referred jaw with overlapped teeth from the latest Cretaceous Lameta Formation of India [72] to Saraikisaurus minhui. Here main purpose is to present large photo for better understanding. Saraikisaurus minhui is large sized, latest and youngest pterosaurs and have basal characters survived upto end Cretaceous extinction. Its beak ramus is slender with internal pneumatic texture. Its teeth are anteroposteriorly long and transversely compressed, oval to suboval, mostly overlapped and obliquely oriented. Its sockets are close to each other showing large number of teeth as a basal character which is contrary to most of the coeval pterosaurs. The preserved beak ramus is $5.8 \mathrm{~cm}$ long, $2 \mathrm{~cm}$ high and $1 \mathrm{~cm}$ wide. The first tooth on preserved dentary beak ramus is $6 \mathrm{~mm}$ anteroposteriorly and $4 \mathrm{~mm}$ transversely wide, the second tooth is $8 \mathrm{~mm}$ anteroposteriorly and $4 \mathrm{~mm}$ transversely wide, the third tooth is $6 \mathrm{~mm}$ anteroposteriorly and $4 \mathrm{~mm}$ transversely wide, the fourth tooth is $7 \mathrm{~mm}$ anteroposteriorly and $4 \mathrm{~mm}$ transversely wide, the fifth tooth is $9 \mathrm{~mm}$ anteroposteriorly and $5 \mathrm{~mm}$ transversely wide, sixth tooth is small in size and may showing replacement tooth, the tooth seven is $4 \mathrm{~mm}$ anteroposteriorly and $3 \mathrm{~mm}$ transversely wide and the eight tooth is $6 \mathrm{~mm}$ anteroposteriorly and $4 \mathrm{~mm}$ transversely wide (Figure 13). These measurements reveal that the transverse widths are mostly constant and also half of anteroposteriorly length. 


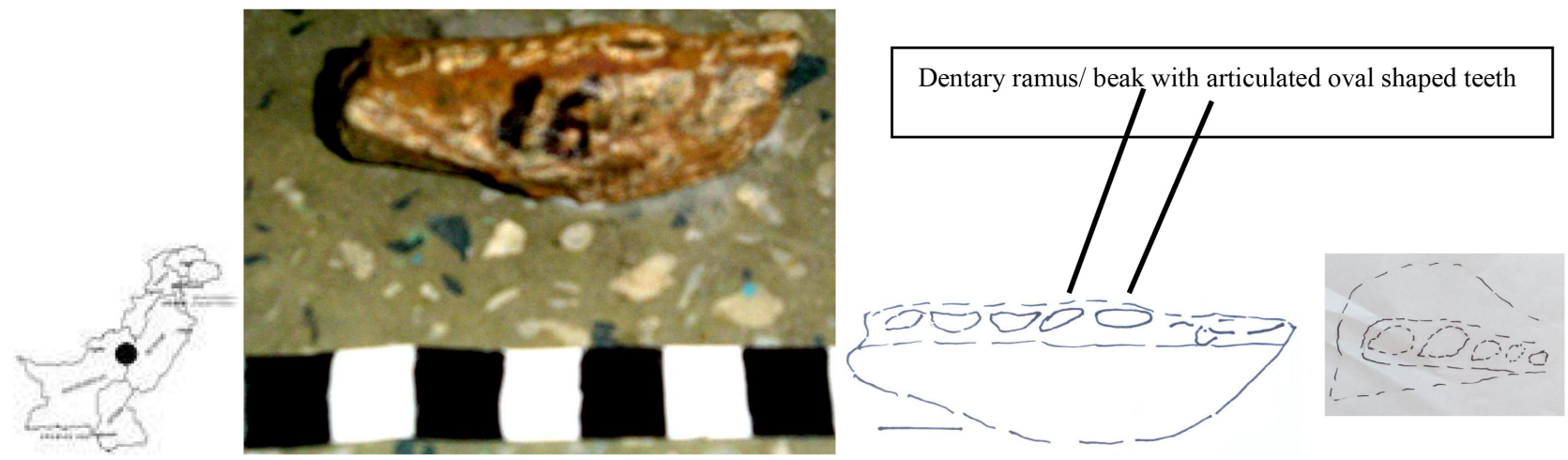

Figure 13. Saraikisaurus minhui holotypic and referred fossils. Photo/P1, Map of Pakistan showing Saraikisaurus minhui pterosaur Topkinwa type locality (black circle). P2, P3, image and line drawing of Saraikisaurus minhui holotypic lower beak/dentary ramus MSM-157-16 with articulated teeth found from Top Kinwa 16 locality of Vitakri dome, Barkhan District, Balochistan, Pakistan. P4, estimated line drawing of teeth in jaw reported from Kotah, Rajasthan, India [72] was referred [9] to Saraikisaurus minhui. Scale, each black/white digit is $1 \mathrm{~cm}$. Scale bar in line drawing is $1 \mathrm{~cm}$.

All the teeth crown are eroded. The teeth are heterodont in size. The teeth central cavity and peripheral bone are dominantly exposed as cross section. Most of the teeth are obliquely set having direction from anterolaterally to medioposteriorly and show overlapping with each others. Saraikisaurus minhui pterosaur is freshwater riverine pterosaur distributed in Indo-Pakistan while the other Jurassic Rhamphorhynchus [74] and Campylognathoides indicus [75] are the lacustrine pterosaurs from Indo-Pakistan subcontinent.

\section{Conclusions}

Two theropods Vitakridrinda and Vitakrisaurus are recognized from Pakistan. Three mesoeucrocodiles are recognized from Indo-Pakistan like Induszalim which consists of circular or subcircular teeth or slightly compressed teeth, the Sulaimanisuchus which consists of moderately compressed teeth, and the Pabwehshi which consists of strongly compressed teeth, while all these 3 taxa have distinct teeth orientations and morphologies. A pterosaur Saraikisaurus minhui recognized from the latest Cretaceous of Indo-Pakistan. Four Poripuchian most derived titanosaur were recognized from Indo-Pakistan like Pakisaurus [6] and Isisaurus [6] [76] pakisaurid poripuchian and Gspsaurus [7] and Saraikimasoom [8] gspsaurid poripuchian titanosaurs. Beside these some other biota were recently recognized from Pakistan [9]. Most of these latest Cretaceous vertebrates have cranial and postcranial skeletons and show strong link to Gondwana lands like Madagascar and Malawi (Africa) and Argentina and Brazil (South America). However some features show correlation with Laurasian taxa. These vertebrates have significant cranial and postcranial fossils for paleobiogeography, comparisons, systematic and phylogenetic studies.

\section{Conflicts of Interest}

The authors declare no conflicts of interest regarding the publication of this paper. 


\section{References}

[1] Malkani, M.S. (2009) New Balochisaurus (Balochisauridae, Titanosauria, Sauropoda) and Vitakridrinda (Theropoda) Remains from Pakistan. Sindh University Research Journal (Science Series), 41, 65-92.

[2] Malkani, M.S. (2019) Cretaceous Stratigraphy of Pakistan. Open Journal of Geology, 9, 671-673. https://doi.org/10.4236/ojg.2019.910071

[3] Malkani, M.S. (2006) Lithofacies and Lateral Extension of Latest Cretaceous Dinosaur Beds from Sulaiman Foldbelt, Pakistan. Sindh University Research Journal (Science Series), 38, 1-32.

[4] Malkani, M.S. and Mahmood Z. (2017) Stratigraphy of Pakistan. Geological Survey of Pakistan, 24, 1-134.

[5] Malkani, M.S. and Mahmood, Z. (2016) Revised Stratigraphy of Pakistan. Geological Survey of Pakistan, 127, 1-87.

[6] Malkani, M.S. (2020) Pakisaurus balochistani (Poripuchia, Slender Titanosauria, Sauropoda) Associated Skeletons from the Latest Maastrichtian Vitakri Formation of Pakistan and Referred Fossils from India; Filling of Significant Missing Links of Isisaurus colberti (Poripuchia, Slender Titanosauria, Sauropoda) Found from $\mathrm{Pa}$ kistan. Open Journal of Geology, 10, 408-447. https://doi.org/10.4236/ojg.2020.104019

[7] Malkani, M.S. (2020) First Skull of Medium Sized Titanosaur from Indo-Pakistan Subcontinent Found from the Latest Maastrichtian Vitakri Formation of Pakistan; Associated Cranial and Postcranial Skeletons of Gspsaurus pakistani (Poripuchia, Stocky Titanosauria, Sauropoda) from Pakistan and India. Open Journal of Geology, 10, 448-489. https://doi.org/10.4236/ojg.2020.104020

[8] Malkani, M.S. (2020) First Snout with Complete Teeth Row of Titanosaur from Indo-Pakistan Subcontinent Found from the Latest Maastrichtian Vitakri Formation of Pakistan; Associated Cranial and Postcranial Skeletons of Saraikimasoom vitakri (Poripuchia, Stocky Titanosauria, Sauropoda) from Pakistan and Referred Fossils from India. Open Journal of Geology, 10, 368-407. https://doi.org/10.4236/ojg.2020.104018

[9] Malkani, M.S. (2019) Recently Discovered Basilosaurid, Baluchithere Rhinoceros, Horses, Sea Cow, Proboscidean, Eucrocodile, Pterosaurs, Plesiosaur, Fishes, Invertebrates and Wood Fossils, Tracks and Trackways of Dinosaurs from Pakistan; Comparison of Recognized Four Titanosaur Taxa of Indo-Pakistan with Madagascar. Open Journal of Geology, 9, 919-955. https://doi.org/10.4236/ojg.2019.912098

[10] Malkani, M.S. (2019) Large Titanosaur from Indo-Pakistan Peninsula. Open Journal of Geology, 9, 635-638. https://doi.org/10.4236/ojg.2019.910061

[11] Malkani, M.S. (2019) Medium Sized Stocky Titanosaur from South Asia. Open Journal of Geology, 9, 631-634. https://doi.org/10.4236/ojg.2019.910060

[12] Malkani, M.S. (2019) Smallest Titanosaur from Indo-Pakistan Landmass. Open Journal of Geology, 9, 627-630. https://doi.org/10.4236/ojg.2019.910059

[13] Malkani, M.S. (2019) Vitakrisaurus saraiki Theropod from South Asia. Open Journal of Geology, 9, 643-645. https://doi.org/10.4236/ojg.2019.910063

[14] Malkani, M.S. (2019) Induszalim bala Mesoeucrocodile from Pakistan. Open Journal of Geology, 9, 623-626. https://doi.org/10.4236/ojg.2019.910058.

[15] Malkani, M.S. (2015) Dinosaurs, Mesoeucrocodiles, Pterosaurs, New Fauna and Flora from Pakistan. Geological Survey of Pakistan, Information Release, 823, 1-32. 
[16] Malkani, M.S. (2010) New Pakisaurus (Pakisauridae, Titanosauria, Sauropoda) Remains and Cretaceous Tertiary (K-T) Boundary from Pakistan. Sindh University Research Journal (Science Series), 42, 39-64.

[17] Malkani, M.S. (2008) Marisaurus (Balochisauridae, Titanosauria) Remains from the Latest Cretaceous of Pakistan. Sindh University Research Journal (Science Series), 40, 55-78.

[18] Malkani, M.S. (2006) Biodiversity of Saurischian Dinosaurs from the Latest Cretaceous Park of Pakistan. Journal of Applied and Emerging Sciences, 1, 108-140.

[19] Wilson, J.A., Sereno, P.C., Srivastava, S., Bhatt, D.K., Khosla, A. and Sahni, A. (2003) A New Abelisaurid (Dinosauria, Theropoda) from the Lameta Formation (Cretaceous, Maastrichtian) of India. Contributions from the Museum of Paleontology, University of Michigan, 31, 1-42.

[20] Novas, F.E., Chatterjee, S., Rudra, D.K. and Datta, P.M. (2010) Rahiolisaurus gujaratensis, n. gen. n. sp., a New Abelisauroid Theropod from the Late Cretaceous of India. In: Bandyopadhyay, S., Ed., New Aspects of Mesozoic Biodiversity, Springer-Verlag, Berlin, 45-62. https://doi.org/10.1007/978-3-642-10311-7 3

[21] Huene, F.V. and Matley, C.A. (1933) Cretaceous Saurischia and Ornithischia of the central Provinces of India. Paleontologia Indica, 21, 1-74.

[22] Owen, R. (1842) Report on British Fossil Reptiles, Pt. II. Reptiles. Report of the British Association for the Advancement of Science, 1841, 60-204.

[23] Marsh, O.C. (1881) Classification of the Dinosauria. American Journal of Science, 23, 81-86. https://doi.org/10.2475/ajs.s3-23.133.81

[24] Marsh, O.C. (1884) Principal Characters of American Jurassic Dinosaurs. Part VIII. The Order Theropoda. American Journal of Science, 27, 329-341. https://doi.org/10.2475/ajs.s3-27.160.329

[25] Bonaparte, J.F. (1991) The Gondwanan Theropod Families Abelisauridae and Noasauridae. Historical Biology, 5, 11-25. https://doi.org/10.1080/10292389109380385

[26] Malkani, M.S. (2010) Updated Stratigraphy and Mineral Potential of Sulaiman (Mid. Indus) Basin, Pakistan. Sindh University Research Journal (Science Series), 42, 39-66.

[27] Malkani, M.S. (2017) Theropod Dinosaurs and Mesoeucrocodiles from Pakistan: A Review. In: Daekyo Cheong, Young Il Lee and Daewoo Kim (eds), Commemoration of the 70 th Anniversary of the Geological Society of Korea, Proceedings and Fieldguide book for the Fifth International Symposium of International Geoscience Programme IGCP Project 608 "Cretaceous Ecosystems and Their Responses to Paleoenvironmental Changes in Asia and the Western Pacific", October 22-28, 2017, Jeju Island, Korea, 63-66.

[28] Chatterjee, S. (1978) Indosuchus and Indosaurus, Cretaceous Carnosaurs from India. Journal of Paleontology, 52, 570-580.

[29] Smith, N.D., Makovicky, P.J., Hammer, W.R. and Currie, P.J. (2007) Osteology of Cryolophosaurus elliotti (Dinosauria: Theropoda) from the Early Jurassic of Antarctica and Implications for Early Theropod Evolution. Zoological Journal of the Linnean Society, 151, 377-421. https://doi.org/10.1111/j.1096-3642.2007.00325.x

[30] Fiorillo, A.R. and Currie P.J. (1994) Theropod Teeth from the Judith River Formation (Upper Cretaceous) of South-Central Montana. Journal of Vertebrate Paleontology, 14, 74-80. https://doi.org/10.1080/02724634.1994.10011539

[31] Currie, P.J., Rigby, Jr. and Sloan, R. (1990) Theropod Teeth from the Judith River 
Formation of Alberta, Canada. In: Carpenter, K. and Currie, P.J., Eds., Dinosaur Systematic, Approaches and Perspectives, Cambridge University Press, New York, 107-125. https://doi.org/10.1017/CBO9780511608377.011

[32] Smith, J.B., Vann, D.R. and Dodson, P. (2005) Dental Morphology and Variation in Theropod Dinosaurs: Implications for the Taxonomic Identification of Isolated Teeth. The Anatomical Record, Part A, 285, 699-736. https://doi.org/10.1002/ar.a.20206

[33] D'Amore, D.C. (2009) A Functional Explanation for Denticulation in Theropod Dinosaur Teeth. The Anatomical Record, 292, 1297-1314. https://doi.org/10.1002/ar.20977

[34] Lindoso, R.M., Medioros, M.A., Carvalho, I.S. and Marinho, T.S. (2012) Masaikasaurus like Theropod Teeth from Alcantara Formation, Sao Luis Basin (Cenomanion), Northeastern Brazil. Cretaceous Research, 36, 119-124. https://doi.org/10.1016/j.cretres.2012.03.002

[35] Mathur, U.B. and Srivastava S. (1987) Dinosaur Teeth from Lameta Group (Upper Cretaceous) of Kheda, Gujurat. Journal of the Geological Society of India, 29, 554-566.

[36] Tortosa, T., Buffetaut, E., Vialle, N., Dutour, Y., Turini, E. and Cheylan, G. (2013) A New Abelisaurid Dinosaur from the Late Cretaceous of Southern France: Palaeobiogeographical Implications. Annales de Paléontologie, 100, 63-86. https://doi.org/10.1016/j.annpal.2013.10.003

[37] Bonaparte, J.F., Novas, F.E. and Coria, R.A. (1990) Carnotaurus sastrei Bonaparte, the Horned, Lightly Built Carnosaur from the Middle Cretaceous of Patagonia. Natural History Museum of Los Angeles County, Contributions in Science, 416, $1-42$.

[38] Gilmore, C.W. (1920) Osteology of the Carnivorous Dinosauria in the United States National Museum, with Special Reference to the Genera Antrodemus (Allosaurus) and Ceratosaurus. Bulletin of the United States Natural Museum, 110, 1-159. https://doi.org/10.5962/bhl.title.61883

[39] Madsen, J.H. (1976) Allosaurus fragilis: A Revised Osteology. Utah Geological and Mineral Survey Bulletin, 109, 1-163.

[40] Currie, P.J. and Zhao, X. (1993) A New Carnosaur (Dinosauria, Theropoda) from the Jurassic of Xinjiang, People's Republic of China. Canadian Journal of Earth Science, 30, 2037-2081. https://doi.org/10.1139/e93-179

[41] Carrano, M.T., Sampson, S.D. and Forster, C. (2002) The Osteology of Masiakasaurus knopfleri, a Small Abelisauroid (Dinosauria:Theropoda) from the Late Cretaceous of Madagascar. Journal of Vertebrate Paleontology, 22, 510-534. https://doi.org/10.1671/0272-4634(2002)022[0510:TOOMKA]2.0.CO;2

[42] Falconer, H. (1868) Memorandum of Two Remarkable Vertebrae, Sent by Dr. Oldham from Jubbalpur-Spilsbury's Bed. Paleontological Memoirs and Notes of the Late Hugh Falconer, 1, 418-419.

[43] Lydekker, R. (1877) Notes of New and Other Vertebrata from Indian Tertiary and Secondary Rocks. Geological Survey of India, 10, 30-43.

[44] Rauhut, O.W.M. (2003) Interrelationships and Evolution of Basal Theropod Dinosaurs. Special Papers in Palaeontology, 69, 1-215.

[45] Morell, V. (1997) The Origin of Birds: The Dinosaur Debate. Audubon Magazine, 99, 36-45.

[46] Carpenter, K. (2002) Forelimb Biomechanics of Nonavian Theropod Dinosaurs in Predation. Senckenbergiana Lethaea, 82, 59-76. https://doi.org/10.1007/BF03043773 
[47] Wilson, J.A. Malkani, M.S. and Gingerich, P.D. (2001) New Crocodyliform (Reptilia, Mesoeucrocodylia) Form the Upper Cretaceous Pab Formation of Vitakri, Balochistan (Pakistan). Contributions from Museum of Paleontology, University of Michigan, 30, 321-336.

[48] Hay, O.P. (1930) Second Bibliography and Catalogue of the Fossil Vertebrata of North America, Volume 2. Carnegie Institution of Washington, 390, 1-1074.

[49] Whetstone, K.N. and Whybrow, P.J. (1983) A "Cursorial" Crocodilian from the Triassic of Lesotho (Basutoland), Southern Africa. Occasional Papers of the $\mathrm{Mu}$ seum of Natural History, University of Kansas, 106, 1-37.

[50] Malkani, M.S. (2014) Theropod Dinosaurs and Mesoeucrocodiles from the Terminal Cretaceous of Pakistan. Abstract Volume of 2nd Symposium of International Geoscience Program (IGCP 608) "Cretaceous Ecosystem of Asia and Pacific", 4-6 September 2014, Tokyo, 169-172.

[51] Malkani, M.S. (2006) First Rostrum of Carnivorous Vitakridrinda (Abelisaurids Theropod dinosaur) Found from the Latest Cretaceous Dinosaur Beds (Vitakri) Member of Pab Formation, Alam Kali Kakor of Vitakri Area, Barkhan District, Balochistan, Pakistan. Sindh University Research Journal (Science Series), 38, 5-24.

[52] Montefeltro, F.C., Larsson, H.C.E. and Langer, M.C. (2011) A New Baurusuchid (Crocodyliformes, Mesoeucrocodylia) from the Late Cretaceous of Brazil and the Phylogeny of Baurusuchidae. PloS ONE, 6, e21916. https://doi.org/10.1371/journal.pone.0021916

[53] Huxley, T.H. (1875) On Stagonolepis Robertsoni, and on the Evolution of the Crocodilia. Quarterly Journal of the Geological Society of London, 31, 423-438. https://doi.org/10.1144/GSL.JGS.1875.031.01-04.29

[54] Clark, J.M. (1994) Patterns of Evolution in Mesozoic Crocodyliformes. In: Fraser, N.C. and Sues, H.-D., Eds., In the Shadow of the Dinosaurs, Harvard University Press, Cambridge, 83-97.

[55] Cotts, L., Pinheiro, A.E.P., Marinho, T.S., Carvalho, I.S. and Dario, F.D. (2017) Postcranial Skeleton of Campinasuchus dinizi (Crocodyliformes, Baurusuchidae) from the Upper Cretaceous of Brazil, with Comments on the Ontogeny and Ecomorphology of the Species. Cretaceous Research, 70, 163-188. https://doi.org/10.1016/j.cretres.2016.11.003

[56] Nobre, P.H. and Carvalho, I.S. (2006) Adamantinasuchus navae: A New Gondwanan Crocodylomorpha (Mesoeucrocodylia) from the Late Cretaceous of Brazil. Gondwana Research, 10, 370-378. https://doi.org/10.1016/j.gr.2006.05.008

[57] Carvalho, I.S. and Bertini, R.J. (1999) Mariliasuchus. Um Novo Crocodylomorpha (Notosuchia) do Cret_aceo da Bacia Bauru, Brasil. Geologia Colombiana, 24, 83-105.

[58] Malkani, M.S., Wilson, J.A. and Gingerich, P.D. (2020) (In Process) Cranial Fossil Assemblages of Mesoeucrocodiles from the Upper Cretaceous of Balochistan ( $\mathrm{Pa}-$ kistan).

[59] Marinho, T.S., Iori, F.V., Carvalho, I.S. and Vanconcellos, F.M. (2013) Gondwanasuchus scabrosus gen. et sp. nov., a new terrestrial predatory crocodyliform (Mesoeucrocodylia: Baurusuchidae) from the Late Cretaceous Bauru Basin of Brazil. Cretaceous Research, 44, 104-111. https://doi.org/10.1016/j.cretres.2013.03.010.

[60] Carvalho, I.S., Ribeiro, L.C.B. and Avilla, L.S. (2004) Uberabasuchus terrificus sp. nov., a New Crocodylomorpha from the Bauru Basin (Upper Cretaceous), Brazil. Gondwana Research, 7, 975-1002. https://doi.org/10.1016/S1342-937X(05)71079-0

[61] Iori, F.V. and Carvalho, I.S. (2018) The Cretaceous Crocodyliform Caipirasuchus: Behavioral Feeding Mechanisms. Cretaceous Research, 84, 181-187. 
https://doi.org/10.1016/j.cretres.2017.11.023

[62] Carvalho, I.S., Vasconcellos, F.M. and Tavares, S.A.S. (2007) Montealtosuchus arrudacamposi, a New Peirosaurid Crocodile (Mesoeucrocodylia) from the Late Cretaceous Adamantina Formation of Brazil. Zootaxa, 1607, 35-46.

https://doi.org/10.11646/zootaxa.1607.1.3

[63] Iori, F.V., Carvalho, I.S., Marinho, T.S. and Santos Frare L.A. (2018) Cranial Morphology of Morrinhosuchus luziae (Crocodyliformes, Notosuchia) from the Upper Cretaceous of Bauru Basin, Brazil. Cretaceous Research, 86, 41-52. https://doi.org/10.1016/j.cretres.2018.02.010

[64] Carvalho, I.S., Campos, A.C.A. and Nobre, P.H. (2005) Baurusuchus salgadoensis, a New Crocodylomorpha from the Bauru Basin, Brazil. Gondwana Research, 8, 11-30. https://doi.org/10.1016/S1342-937X(05)70259-8

[65] Buckley, G.A. and Brochu, C.A. (1999) An Enigmatic New Crocodile from the Upper Cretaceous of Madagascar. Palaeontology, 60, 149-175.

[66] Buckley, G.A., Brochu, C.A., Krause, D.W. and Pol, D. (2000) A Pug-Nosed Crocodyliform from the Late Cretaceous of Madagascar. Nature, 405, 941-944. https://doi.org/10.1038/35016061

[67] Sues, H.-D. and Taquet, P. (1979) A Pachycephalosaurid Dinosaur from Madagascar and a Laurasia-Gondwanaland Connection in the Cretaceous. Nature, 279, 633-635. https://doi.org/10.1038/279633a0

[68] Colberti, E.H. (1946) Sebecus, Representative of a Peculiar Suborder of Fossil Crocodilia from Patagonia. Bulletin of American Museum of Natural History, 87, 217-270.

[69] Wu, X.-C. and Sues, H.-D. (1996) Anatomy and Phylogenetic Relationships of Chimaerosuchus paradoxus, an Unusual Crocodyliform Reptile from the Lower Cretaceous of Hubei, China. Journal of Vertebrate Paleontology, 16, 688-702. https://doi.org/10.1080/02724634.1996.10011358

[70] Antunes, M.T. (1975) Iberosuchus, Crocodile Sebecosuchian Nouveau, l'Eocène ibérique au nord de la Chaîne central, et l'origine du canyon de Nazaré. Comunicaçoes dos Servicos Geologicos de Portugal, 59, 285-330.

[71] Ortega, F., Buscalioni, A.D. and Gasparini, Z. (1996) Reinterpretation and New Denomination of Atacisaurus crassiproratus (Middle Eocene; Issel, France) as cf. Iberosuchus (Crocodylomorpha, Metasuchia). Geobios, 29, 353-364. https://doi.org/10.1016/S0016-6995(96)80037-4

[72] Dubey, V.S. and Narain, K. (1946) A Note on the Occurrence of Pterosauria in India. Current Science, 15, 287-288.

[73] Sahni, A. (2001) Dinosaurs of India. National Book Trust, Delhi, 110 p.

[74] Rao, C.N. and Shah, S.C. (1967) On Occurrence of Pterosaur from the Kota-Maleri Beds of Chanda District (India). Geological Survey of India, 92, 315-318.

[75] Jain, S.L. (1974) Jurassic Pterosaur from India. Journal of the Geological Society of India, 15, 330-335.

[76] Jain, S.L. and Bandyopadhyay S. (1997) New Titanosaurid (Dinosauria: Sauropoda) from Late Cretaceous of Central India. Journal of Vertebrate Paleontology, 17, 114-136. https://doi.org/10.1080/02724634.1997.10010958 